\title{
Hegemonía cultural disputada en México. Las revistas Nexos y Vuelta enfrentadas (1990-1992)*
}

\section{Resumen}

Este artículo profundiza en el debate entre dos grupos de intelectuales reunidos en la revista Nexos y Vuelta por dos eventos públicos con invitados internacionales y nacionales organizados en México entre 1990 y 1992. Se pretende entender el papel de estos intelectuales como facilitadores del cambio en la relación del campo intelectual con el Estado bajo el ideario y las reformas estructurales neoliberales. Se hace una lectura del desarrollo de esta relación desde los setenta; se caracteriza cada una de las revistas y se sigue su evolución hasta la reconfiguración neoliberal de los ochenta. Las fuentes utilizadas fueron publicaciones de los intelectuales destacados de ambos grupos en torno a los debates consignados en publicaciones periódicas coincidentes con cada momento. Ambos grupos se adaptaron a los cambios que imponía el Estado en su relación con el campo intelectual y resultaron privilegiados como mediadores en esta relación, lo que culminaría con un enfrentamiento por una mayor preeminencia.

\section{Palabras clave \\ Tesauro: México, hegemonía cultural, intelectuales, neoliberalismo.}

Referencia bibliográfica para citar este artículo: Caballero Escorcia, Boris Alexánder. "Hegemonía cultural disputada en México. Las revistas Nexos y Vuelta enfrentadas (1990-1992)". Anuario de Historia Regional y de las Fronteras 25.2 (2020): 149-186.

Boris Alexánder Caballero Escorcia: Candidato a doctor en Ciencias Sociales de la Universidad Autónoma Metropolitana de Xochimilco. Magister en Enseñanza de la Historia por la Universidad Michoacana San Nicolás Hidalgo. Código ORCID: 0000-0002-5574-2234. Correo electrónico: boricaba@gmail.com

\footnotetext{
* Este artículo es el resultado de una investigación de mucho más largo aliento realizada en el marco de mis estudios de doctorado en la elaboración del proyecto de investigación para optar al grado de doctor en Ciencias Sociales por la Universidad Autónoma Metropolitana Unidad Xochimilco titulado: "Discurso político y contenidos de historia nacional en los libros de texto gratuito de primaria. México 1970-2011". Este artículo como el proyecto de investigación del doctorado no hubiese sido posible sin la financiación de la beca nacional del Consejo Nacional de Ciencia y Tecnología (CONACYT) otorgada por los Estados Unidos Mexicanos a estudiantes de posgrado en programas de reconocida de alta calidad.
} 


\title{
Cultural Hegemony Disputed in Mexico. The Magazines Nexos and Vuelta Faced (1990-1992)
}

\begin{abstract}
This article deepens the debate between two groups of intellectuals gathered in the Nexos and Vuelta magazines for two events organized in Mexico between 1990 and 1992. It is intended to understand the role of these intellectuals as facilitators of the change in the relationship of the intellectual field with the State under the neoliberal ideology and structural reforms. It is made analysis of the development of this relationship since the 1970s, each of the magazines is characterized and its evolution is followed until the neoliberal reconfiguration the 1980s. The sources used were publications of the outstanding intellectuals of both groups around the debates, press and periodicals coinciding with each moment. Both groups adapted to the changes imposed by the State in their relationship with the intellectual field and were privileged as mediators in such relationship, which would culminate in a confrontation for greater preeminence.
\end{abstract}

Keywords

Tesauro: Mexico, Cultural Hegemony, Intellectuals, Neoliberalism.

\section{Hegemonia cultural disputada no México. As revistas Nexos e Vuelta enfrentaram (1990-1992)}

\section{Resumo}

Este artigo aprofunda o debate entre dois grupos de intelectuais reunidos nas revistas Nexos e Vuelta para dois eventos organizados no México entre 1990 e 1992. Pretende-se compreender o papel desses intelectuais como facilitadores da mudança na relação do campo intelectual com o Estado sob a ideologia e reformas estruturais neoliberais. Foi feita uma leitura do desenvolvimento dessa relação desde os anos setenta, cada uma das revistas é caracterizada e sua evolução é seguida até a reconfiguração neoliberal dos anos oitenta. As fontes utilizadas foram publicações dos intelectuais destacados de ambos os grupos em torno dos debates, imprensa e periódicos coincidentes com cada momento. Ambos os grupos se adaptaram às mudanças impostas pelo Estado em sua relação com o campo intelectual e foram privilegiados como mediadores nessa relação, o que culminaria em um confronto por maior preeminência.

Palavras chave

Tesauro: México, hegemonia cultural, intelectuais, neoliberalismo 


\section{Introducción}

Este artículo es el resultado de una investigación de mucho más largo aliento realizada en el marco de mis estudios de doctorado sobre la transformación que sufre el discurso político de la nación mexicana en el último tercio del siglo XX y su relación con la modificación en las orientaciones y sentidos de los contenidos de enseñanza de historia nacional en México. En este cambio del discurso político sobre el pasado que opera en la década de los ochenta y noventa los intelectuales juegan un papel fundamental en la conformación de una transformación del discurso oficial sobre la nación, el Estado y la historia nacional.

De esta manera, el debate suscitado entre febrero y abril de 1992, en torno a la organización del Coloquio de Invierno por los intelectuales nucleados alrededor de dos revistas destacadas del campo intelectual mexicano a principios de la década de los noventa, marcó la evidencia de la ocurrencia de cambios fundamentales en las relaciones entre la cultura y el Estado. Por un lado, la revista Vuelta, dirigida por Octavio Paz, y, por el otro, la revista Nexos, dirigida por Héctor Aguilar Camín, van a enfrentarse por el control sobre el campo y la influencia en las políticas culturales. Respondían ambas revistas a una tradición, entonces aún instalada, de tipo corporativista donde el Estado cobija la actividad intelectual y le da sustento para controlarla, utiliza mecanismos que neutralizan su potencial crítico para el establecimiento mediante la incorporación de intelectuales al campo de la función pública o mediante el apoyo y subvención de actividades culturales de interés para los intelectuales. No obstante, este papel tradicionalmente corporativista del Estado mexicano cambiará en el contexto neoliberal, y tanto Nexos como Vuelta van a adaptarse a estos cambios y ubicarse de manera privilegiada como intermediadores entre el sistema político y el campo cultural mexicano en la búsqueda de legitimidad del poder en un momento de crisis que, además, implicaba cambios y trasformaciones.

Estas dos revistas van a dominar de una manera hegemónica la vida intelectual en México en un contexto nacional signado por la crisis de la hegemonía del partido de gobierno Partido Revolucionario Institucional (PRI), por cambios constitucionales dirigidos a una mayor democratización de los poderes conformadores del Estado y por la emergencia de la propuesta neoliberal de reestructuración del papel del Estado en la economía; mientras que el contexto internacional se distinguía por la crisis del socialismo real y la caída del antiguo bloque socialista. Estos contextos entrecruzados determinarán la configuración del campo intelectual mexicano en las últimas décadas del siglo XX, y el enfrentamiento entre Nexos y Vuelta expresará las disputas y contradicciones dentro del campo.

Este momento implica cambios en las relaciones del Estado con el mundo de la cultura y los escenarios de producción de bienes simbólicos en el que aparentemente estas relaciones se debilitaban. El interés de este artículo es dar cuenta de las posturas sobre el Estado y su papel en el mundo de la cultura de algunos intelectuales que tenían una posición privilegiada en la relación con el poder político; intelectuales que para este momento de cambios estaban reunidos alrededor de dos revistas que oficiaban 
como sendos proyectos culturales: Vuelta y Nexos. Este tema remite necesariamente a planteamientos como los de Roderic A. Camp cuando afirma que no se puede entender la estructura de la vida intelectual, sino se incluye en el análisis al sistema político. ${ }^{1} \mathrm{Y}$ si el sistema político sufre cambios necesariamente estos cambios se manifestarán en la estructura de la vida intelectual que tendrá su expresión en las posturas y opiniones que los intelectuales.

Del mismo modo, resulta de gran utilidad para este trabajo los aportes de Pierre Bourdieu con relación al concepto de campo. ${ }^{2}$ En un planteamiento coincidente con Camp considera que el campo intelectual "está incluido en un tipo específíco de campo político, que atribuye a la fracción intelectual y artística una posición determinada". ${ }^{3}$ No obstante, en la medida que en la sociedad se extienden las relaciones de mercado y se urbaniza bajo el impulso de la modernización capitalista y una división social del trabajo más amplia y profunda, se crea también un mercado de bienes simbólicos y todo un grupo destinado a la producción de bienes simbólicos que opera movido por gratificaciones económicas y simbólicas; y estos productores son los intelectuales.

En este proceso la creación intelectual adquiere una mayor independencia sobre el poder político hasta alcanzar un importante grado de autonomía, sin embargo, la relación y determinación continúa, y a determinada estructura del campo intelectual corresponde un campo ideológico y político. Por más grande que sea esta autonomía, para Bourdieu, el campo intelectual siempre está determinado en su estructura y función por la posición que ocupa al interior del campo de poder. ${ }^{4}$ Así, incluso en un momento en el que el Estado corporativista, para el caso mexicano, entra en crisis y busca retirarse del papel tradicional de control y gestión del campo cultural e intelectual, igualmente existe una relación entre el campo político y el campo intelectual de la cual

\footnotetext{
${ }^{1}$ Camp se interesa en su estudio sobre los intelectuales y el Estado en México en el siglo pasado sobre las percepciones de los intelectuales acerca del Estado y de los políticos y las relaciones entre uno y otro grupo. De este modo, señala que "Un examen de la estructura de la vida intelectual debe incluir al sistema político", lo cual "implica que la relación entre el Estado y el intelectual tiene un efecto significativo sobre muchas cuestiones intelectuales", efecto que se manifiesta "se trate de la censura, la educación, las oportunidades de carrera o el activismo político", por lo que se conseguirá "un entendimiento incompleto del intelectual [...] si se excluye al sistema político". Roderic Camp, Los intelectuales y el Estado en el México del siglo XX (México: Fondo de Cultura Económica, 1988) 25.

${ }^{2}$ El concepto de campo es fundamental para entender las relaciones entre los intelectuales y el poder político, pues entiende la sociedad como un escenario de interdependencia y mutuas determinaciones de múltiples campos articulados en una unidad configurada históricamente. Campo como metáfora del campo de fuerza para entenderlo como espacio de reunión de intereses y relaciones de poder en lucha, enfrentamiento y tensión por las diferencias de capital y las distintas posiciones de los agentes que se relacionan entre ellos por reglas y códigos estatuidos por el campo, entramado de posiciones, relaciones y reglas que cambian históricamente y según las transformaciones que sufren los otros campos se afectaran entre ellos a tono con el peso relativo de cada uno con respecto al otro. Un agente de un campo con una posición relativa con respecto a este también ocupa una posición con diferenciales de capital con relación a otros campos. Pierre Bourdieu, Sociología y cultura (México: Editorial Grijalbo, 1984) 135-141.
}

${ }^{3}$ Pierre Bourdieu, Campo de poder, campo intelectual. Itinerario de un concepto (Buenos Aires: Editorial Montressor, 2002) 99.

"Bourdieu, "Campo de poder" 104-106. 
hay que dar cuenta. Aquí, en este artículo, intentaremos acercarnos a la evolución de esta relación entre el campo intelectual en México y el poder político, en un contexto donde el Estado redefine su papel bajo el ideario neoliberal, a partir del análisis de las posturas de dos grupos de intelectuales que hegemonizarían el campo a partir de su relación privilegiada con el poder desde su surgimiento en torno a cada una de las revistas hasta el enfrentamiento alrededor de la realización del evento denominado Coloquio de Invierno.

De este modo, se culmina con los eventos que suscitan el debate entre los dos grupos y que mejor expresan sus posiciones respectivas con respecto al campo del poder político: el primero entre el 27 de agosto y el 2 de septiembre de 1990 organizado por el grupo de Vuelta y denominado entonces El siglo XX. La experiencia de la Libertad, evento claramente anticomunista con invitados internacionales algunos de ellos partícipes en la caída del Bloque Socialista; y el segundo, mejor conocido como Coloquio de Invierno, organizado por el grupo en torno a la revista Nexos entre el 10 y 21 de febrero de 1992 bajo el título Los grandes cambios de nuestro tiempo. La situación internacional. América Latina y México, cuya temática iba en abordar la nueva situación de América Latina en un mundo bajo la hegemonía absoluta de Estados Unidos y del capital y con la renovación democrática en varios países. Con base en los debates suscitados en estas dos coyunturas alrededor de cada uno de estos eventos se presenta en este artículo la reconfiguración de la relación entre el Estado y el campo intelectual mexicano desde las posturas planteadas por los intelectuales más destacados implicados, en una época de transición política, económica y cultural.

Se han utilizado como fuentes fundamentales las dos revistas, Vuelta y Nexos, en torno a las cuales se nucleaba cada uno de los grupos de intelectuales que interesa analizar en esta investigación. Por su parte, el semanario Proceso ha sido una buena fuente de contexto sobre las repercusiones del enfrentamiento entre estos dos grupos de intelectuales en el debate público y la ubicación de los argumentos allí esgrimidos que generaron mayor inquietud en la opinión pública. Por otro lado, este trabajo se apoya en los sugerentes estudios aquí referenciados sobre estas revistas o sus intelectuales de autores como Maarten Van Delsen, Claudio Lomnitz, Avital Bloch y Carlos Illades. Los enunciados manifiestos en los textos producidos en este debate marcan la pauta de los derroteros para el análisis de lo que los intelectuales involucrados creen y expresan sobre las relaciones del campo intelectual con el campo de la política y del poder representado en el Estado, lo que indaga sobre los argumentos de cuál es o debería ser la relación de su campo con el Estado.

\section{La apertura y la incorporación del campo al establecimiento. Tensiones y búsquedas de legitimidad}

En la década de los setenta, paralelo a un proceso de incipiente "apertura democrática" empujado por la presión de las clases medias y los desastrosos hechos de la represión de 1968 y 1971 que ponían aún más en cuestión el autoritarismo 
del sistema político mexicano, ${ }^{5}$ el gobierno de Luis Echeverría (1970-1976) lleva adelante una estrategia de recooptación y acercamiento a los intelectuales como parte de su esfuerzo de relegitimar el sistema político mexicano; se requería reoxigenar el discurso político en el terreno de lo ideológico. ${ }^{6}$ En este contexto, el campo intelectual se ha diversificado aún más y logra adquirir espacios de desarrollo con mayor autonomía respecto al Estado y al discurso oficial. Surgen algunos grupos alrededor de publicaciones periódicas que comienzan a ejercer desde el periodismo una crítica al gobierno y sus políticas, poniendo en cuestión el modelo de desarrollo seguido en México y su sistema político.

Es decir, se percibe una mayor democratización en el mundo cultural y de la opinión. Periódicos como Excélsior, bajo la dirección de Julio Scherer García desde 1968 hasta julio de 1976, van a ser espacios de reunión para el debate intelectual en el mundo de la cultura y la opinión política. No obstante, esta apertura intelectual del régimen tenía sus límites y el denominado "el golpe a Excélsior" así lo ejemplifica. Cuando una coalición de trabajadores apoyados y financiados por el gobierno de Echeverría en una Asamblea logran la renuncia de Julio Scherer al periódico, y se convierte de una publicación crítica a un periódico más al servicio del gobierno, en el episodio conocido como "el golpe a Excélsior", los intelectuales que se habían nucleado alrededor también renuncian. ${ }^{7}$ Intelectuales y escritores como Octavio Paz, quien dirigía el suplemento cultural Plural, Gabriel Said, Carlos Monsiváis, Manuel Becerra Acosta, entre otras figuras destacadas y consagradas del campo cultural salen en busca de otros escenarios.

El "golpe a Excélsior" generó un efecto diáspora, pero a la vez multiplicador de iniciativas de publicaciones y desarrollos culturales independientes, fuera del control o financiamiento estatal. Tal como señala Monsiváis: "Scherer en Excélsior comenzó a hacer modificaciones trascendentes, y luego del golpe de Excélsior vinieron" otras publicaciones igualmente críticas, desde el campo de la cultura, del sistema político como "Proceso, unomásuno, La Jornada, Vuelta, Nexos y múltiples

\footnotetext{
${ }^{5}$ En el contexto de una amplia movilización estudiantil que pedía mayores escenarios de participación política y democrática en la vida nacional el 2 de octubre de 1968 se lleva a cabo por parte de elementos de la fuerza armada una masacre en contra de una manifestación estudiantil en la plaza de Tlatelolco en Ciudad de México. En 1971, con un gobierno encabezado por el presidente Luis Echeverría que prometía acabar con la tradicional represión del sistema político mexicano, sin embargo, una manifestación el 10 de junio para recibir a varios de los líderes del 68 que se vieron obligados al exilio después de la masacre fue atacada por una organización paramilitar llamada Los Halcones bajo la complicidad de las fuerzas de seguridad del Estado.

${ }^{6}$ Cf. Camp 280-281; Carlos Monsiváis, "La disidencia crónica", Creación y poder. Nueve retratos de intelectuales, eds. Pilar Jiménez Trejo y Alejandro Toledo (México: Editorial Joaquín Mortiz S.A, 1994) 65.

${ }^{7}$ Este hecho es recordado por buena parte del campo intelectual y de la generación que se conformó intelectualmente en ese entonces, como una muestra de la desconfianza frente al Estado, pues en "el golpe a Excélsior" se culpó a Echeverría como el responsable que buscó la forma de acallar la crítica que la administración de Scherer del periódico permitía se hiciese a su gobierno. Cf. Camp 281; Monsiváis, "La disidencia crónica" 67; Héctor Aguilar Camín, "Retrato después de la batalla", Creación y poder. Nueve retratos de intelectuales, eds. Pilar Jiménez Trejo y Alejandro Toledo (México: Editorial Joaquín Mortíz S.A, 1994) 25; Enrique Krauze, "El historiador liberal", Creación y poder. Nueve retratos de intelectuales, eds. Pilar Jiménez Trejo y Alejandro Toledo (México: Editorial Joaquín Mortíz S.A, 1994) 43.
} 
publicaciones que consolidan el cambio, ya presente también en las regiones: hay por lo menos 10 publicaciones en los estados que reproducen a escala el trabajo de Proceso o de La Jornada. Surge un periodismo más atento a la vida cotidiana, a los problemas de la sociedad, a la cultura como hecho noticioso" ${ }^{8}$ Es decir, parecía instalarse una tendencia de autonomía del campo intelectual mexicano por fuera de los imperativos ideológicos del Estado.

Los setenta es el periodo de esplendor de las publicaciones periódicas en México, pero también es el periodo donde la política del Estado interviene más activamente en el mundo de la producción y distribución de la cultura impresa. Tal como lo registra Cecilia Greaves durante el sexenio de Echeverría, pero también durante el de José López Portillo (1976-1982), la producción editorial y el incentivo del Estado a las publicaciones fue significativo; generó un acceso amplio a la lectura y facilidades para el ejercicio de la escritura y la publicación. ${ }^{9}$ Fue de tal magnitud el cambio en la oferta cultural impresa, que a principios de la década de los ochenta Carlos Monsiváis se atrevería a afirmar que México había logrado un "salto cultural", ${ }^{10}$ refiriéndose a la ampliación de la lectura y la facilidad para acceder al libro a amplios sectores de la población. ${ }^{11}$

En este escenario, historiadores como Luis González y González, Enrique Florescano, y más jóvenes, como Héctor Aguilar Camín y Enrique Krauze, entre algunos otros, establecerían puentes desde la elaboración de la disciplina con el mundo más amplio de la cultura y la literatura. En relación con grandes patriarcas de la cultura mexicana como Octavio Paz y Carlos Fuentes, se consolidarían algunos de los proyectos editoriales y culturales de los ochenta, entre ellos los grupos más dominantes de Vuelta y Nexos, así como alrededor de Carlos Monsiváis durante la existencia del suplemento La cultura en México, donde historiadores y científicos sociales encontrarían una trinchera de opinión desde el ensayo o la literatura sobre la coyuntura y la sociedad mexicana. ${ }^{12}$

\footnotetext{
${ }^{8}$ Monsiváis, "La disidencia crónica" 64.

${ }^{9}$ Cecilia Greaves, "La Secretaría de Educación Pública y la lectura 1960-1985", Historia de la lectura en México, coord. ${ }^{a}$ Pilar Gonzalbo (México: El Colegio de México, 1998) 349-364.

${ }^{10}$ Carlos Monsiváis, "Notas sobre el Estado, la cultura nacional y las culturas populares en México", Cuadernos Políticos 30 (1981): 40-41.

${ }^{11}$ No obstante, este optimismo hay que matizarlo, pues en 1980 se calculaba en tan solo un 6\% de la población mexicana a quienes frecuentaban el mundo académico, compraban y leían libros. Cf. Camp 51. Por su parte, un estudio de Ediciones de Cultura Popular a principios de la década de los ochenta afirmaba que no más del 4\% de la población adquiría libros habitualmente. Greaves 366.

${ }^{12}$ El suplemento ¡La cultura en México, que se publicaba con la revista Siempre!, estuvo de 1972 hasta su culminación en 1987 bajo la dirección de Carlos Monsiváis, al dejar su dirección la mayoría de los colaboradores, incluido Monsiváis, orbitarían en la revista Nexos que abriría sus páginas y consejo editorial a sus antiguos integrantes. Además, esta relación entre las dos publicaciones existió desde el mismo nacimiento de Nexos, pues Héctor Aguilar Camín, periodista de la universidad Iberoamericana y doctor en historia por el Colegio de México, salió del Consejo editorial de La cultura en México, para participar en la creación de Nexos en 1978. Así mismo, Enrique Krauze, por su parte ingeniero del IPN y doctor en Historia del Colegio, compañero de promoción de Aguilar Camín, había colaborado en el suplemento de ¡Siempre! hasta que en 1975 lo abandonó para colaborar con Octavio Paz en Plural y luego en Vuelta.
} 
Lo cultural se configura en la década de los setenta, hasta la década del ochenta, como un campo de despliegue con sus luchas y dinámicas propias, con una mayor autonomía frente al poder político. No obstante, en un sistema como el mexicano donde el Estado ha jugado un papel determinante en la conformación del mundo cultural e intelectual, así como en el surgimiento de las ciencias sociales, su impronta aún se hacía sentir con el empleo de los intelectuales en la diplomacia o en funciones administrativas y públicas en el terreno de la cultura. El Estado seguía siendo un referente de validación para la obtención de apoyos y recursos, aunque las consideraciones y parámetros para su asignación provinieran del propio campo cultural. Sin ejercer la mayoría de las veces una censura directa, sí había una vinculación indirecta de los intelectuales y sus intereses con el Estado y su administración, sin la mediación de la academia o la universidad. Monsiváis, a finales de los ochenta, en el último número de su suplemento, intentaba hacer una distinción legítima entre Estado y gobierno, en defensa del argumento de la preservación de la autonomía de los intelectuales aun si se habitaba o utilizaban los espacios facilitados por el poder, cuando afirmaba:

El Estado usa (más bien usaba) su patrocinio como parte de su campaña de venta de estabilidad: "te protejo para mostrar mi amplitud de criterio" [...] El Estado no es el gobierno, es asunto de todos, le ha costado demasiado a muchas generaciones, y nadie se beneficia con pretender que el Estado es el beso del diablo si patrocina conferencias, exposiciones, recitales, obras de teatro. Esto en todo caso es prueba de la estabilidad, no de las bondades del régimen. ${ }^{13}$

No obstante, en una orilla distinta, Octavio Paz en su artículo "El ogro filantrópico" esboza en 1978 una crítica al Estado mexicano como un aparato que subyuga a la sociedad y que se comporta de manera ambigua entre el sometimiento, la intimidación y la represión autoritaria, por un lado, y la dádiva, el regalo y la protección paternalista por el otro. Allí Paz se ubica en el ideal liberal de la construcción de una nación donde se consolide una sociedad fuerte, en la cual se incluyen los intelectuales, y exista un Estado débil que permita el despliegue de las fuerzas sociales en la conformación de la orientación nacional. De este modo, reivindica en la historia mexicana como ese único momento en el que se realizó este ideal en el periodo de la República Restaurada (1867-1876) antes de la llegada al poder del porfirismo y el establecimiento posrevolucionario que configurarán una sociedad dominada por el Estado como creador de modernización y de instituciones, pero a la vez cargado de elementos atávicos patrimonialistas y antimodernos. Este Estado posrevolucionario, para Paz, es el que no solo permitió, incentivó e instauró la consolidación del capitalismo en México, sino que, además, organizó a los campesinos, a los obreros y a la institucionalidad creadora de la cultura nacional oficial, en la cual encontraron cobijo y se generó una intelectualidad que nace en una relación de dependencia con el Estado. ${ }^{14}$

\footnotetext{
${ }^{13}$ Carlos Monsiváis, "En el vigésimoquinto aniversario de La cultura en México", La cultura en México. 25 años de La cultura en México 1300 (1987) 48

${ }^{14}$ Octavio Paz, "El ogro filantrópico”, Vuelta 21 (1978): 38-44.
} 
Esta postura de Paz guarda su correlato con el papel que él consideraba debía tener un escritor, entendido, además, como intelectual, en la sociedad mexicana. En una entrevista que realiza Julio Scherer para la revista semanario Proceso, de la cual era su director, publicada en dos números consecutivos en diciembre de 1977 y motivada por haber ganado el Premio Nacional de las Letras, Octavio Paz expone su concepción sobre el intelectual y su relación con el poder y el Estado en México. En esa ocasión, Paz señalaba que el deber del escritor es con el lenguaje y su conciencia, no con el país o la sociedad, ${ }^{15}$ y la labor del intelectual con respecto al poder no puede ser otra que su crítica. Para el futuro nobel de literatura, el intelectual debe anteponer sobre todo el cumplimiento de la tarea que lo define: "escribir, investigar, pensar, pintar, construir, enseñar", aunque "la crítica es inseparable del quehacer intelectual", pues es inevitable que el intelectual tropiece tarde o temprano con el poder. Y es en este momento, entonces, cuando "el intelectual descubre que su verdadera misión política es la crítica del poder y de los poderosos". ${ }^{16}$

Para Paz el poder y los poderosos están representados en el Estado, el cual "es la verdadera amenaza" en todo el mundo, que actúa no solo como un "ogro filantrópico" en el caso mexicano, sino que también se comporta como un "monstruo frío" que atormenta en todo el mundo y todo busca centralizarlo y controlarlo al estilo del "Big Brother". ${ }^{17}$ Tal como afirmaría meses después: "el Estado del siglo XX se ha revelado como una fuerza más poderosa que la de los antiguos imperios y como un amo más terrible que los viejos tiranos y déspotas. Un amo sin rostro, desalmado y que obra no como un demonio sino como una máquina". ${ }^{18}$ Es por lo que considera que en México no da espera la crítica a este ánimo centralista y de control del Estado; es tan urgente como "la implantación de una política democrática. El centralismo económico, político, cultural—no es sino una forma más perfecta y terrible del monopolio, es decir, del absolutismo". ${ }^{19}$

Ante la existencia de una instancia como el Estado tan fuerte y tiránico sobre la vida, la labor del intelectual debe ser fortalecer a la sociedad desde su especificidad como creador y conocedor del lenguaje, desde la defensa de su conciencia como ser pensante. Por su parte, definía la conciencia, citando a André Breton, como "aquello que, 'ocurra lo que ocurra, nos lleva a oponernos a todo lo que atente contra la dignidad de la vida'. La conciencia es lo contrario de la razón de Estado". ${ }^{20}$ Lo ideal era que el intelectual entendido "como escritor en las sociedades modernas" se asumiera como "un ser marginal. Y por serlo, justamente, ejerce una función crítica”. Esta función es central para Octavio Paz y solo puede ser ejercida si no se está “en el centro de la

\footnotetext{
15 Julio Scherer García, "Octavio Paz: "Veo una ausencia de proyectos, las ideas se han evaporado", Proceso 58 (1977): 9.

${ }^{16}$ Julio Scherer García, "Octavio Paz: 'La conciencia es lo contrario de la razón de Estado’”, Proceso 57 (1977): 8.

${ }^{17}$ Scherer, "Octavio Paz: "Veo una ausencia" 8.

${ }^{18} \mathrm{Paz}$, "El ogro filantrópico" 38.

${ }^{19}$ Scherer, "Octavio Paz: "Veo una ausencia" 8.

${ }^{20}$ Scherer, "Octavio Paz: 'La conciencia...” 10.
} 
acción, como el político, sino al margen”, pues precisamente en esta marginalidad, en su mantenimiento, estaría la posibilidad del ejercicio de la función crítica que debe caracterizar al escritor, al intelectual: "La eficacia política de la crítica del escritor reside en su carácter marginal, no comprometido con un partido, una ideología o un gobierno". ${ }^{21}$

No obstante, esta "marginalidad" no está en contra de la concepción de Paz, en ese entonces, de asumir responsabilidades en cargos del Estado, con lo que él mismo se justifica. En síntesis, al intelectual donde esté lo debe acompañar su conciencia y compromiso con la moral vinculada con principios y valores universales y trascendentales. Considera que en la realidad mexicana es casi inevitable que un escritor trabaje para el Estado, pero éste siempre estará en la obligación de protestar cuando el accionar del Estado va en contra de su conciencia y de la moral, situación en la cual él se coloca como un ejemplo, cuando renunció a su condición de embajador en protesta por los hechos de represión de 1968. De esta manera, soluciona esta ambigüedad en su planteamiento y se justifica a sí mismo:

En México, todos o casi todos los escritores, sin excluir a gente que fue la independencia misma como Revueltas y Cosió Villegas, hemos servido en el Gobierno. Compromiso peligroso que puede convertirse en pecado mortal si el escritor olvida que su oficio es un oficio de palabras y que entre ellas una de las más cortas y convincentes es NO. Uno de los privilegios del escritor es decir NO al poder injusto. Pero ese NO debe brotar de la conciencia y no de la táctica, la ideología o las necesidades del partido. La función política del escritor depende de su condición de hombre fuera de las combinaciones políticas. El escritor no es el hombre del poder ni el hombre del partido: es el hombre de conciencia. ${ }^{22}$

La relación con el poder de los intelectuales se excusa en la medida que preserven su marginalidad en el campo del ejercicio de la política, de los intereses partidistas y de las adscripciones ideológicas. Marginalidad que implicaba su fidelidad a sus principios, a su conciencia, a la lucha contra la injusticia, y desde la cual debería descansar su crítica moral al Estado, como ese gran “ogro". En conclusión, para Paz "los intelectuales pueden ser útiles dentro del Gobierno... a condición de que sepan guardar las distancias con el Principe". 23

Esta concepción negativa sobre el Estado, así como su postura sobre el papel del escritor como intelectual con relación al Estado, se harán mucho más claras en el marco de la crisis del modelo político y económico heredado de la posrevolución y el surgimiento de un discurso antiestatista desde la propuesta neoliberal que se abría paso como política definitoria de un nuevo modelo de desarrollo para México. Postura que definirá en buena medida la orientación en los debates de Octavio Paz y su grupo de la revista Vuelta.

\footnotetext{
${ }^{21}$ Scherer, "Octavio Paz: "Veo una ausencia" 8.

${ }^{22}$ Scherer, "Octavio Paz: "Veo una ausencia" 8.

${ }^{23}$ Scherer, "Octavio Paz: 'La conciencia” 8.
} 


\section{Neoliberalización del campo cultural. Consolidación de Vuelta y en Nexos}

Lo cultural como un espacio con una mayor autonomía frente al poder político, como un campo de despliegue con sus luchas y dinámicas propias, se configura en las décadas de los setenta y ochenta. No obstante, en un sistema como el mexicano donde el Estado ha jugado un papel determinante en la conformación del mundo cultural e intelectual, así como en el surgimiento de las ciencias sociales, su impronta aún se hacía sentir con el empleo de los intelectuales en la diplomacia o en funciones administrativas y públicas en instituciones de la cultura. El Estado seguía siendo un referente de validación para la obtención de apoyos y recursos, aunque las consideraciones y parámetros para su asignación provinieran del propio campo cultural. Sin ejercer la mayoría de las veces una censura directa, sí había una vinculación indirecta de los intelectuales y sus intereses con el Estado y su administración sin la mediación de la academia o la universidad. Es claro entonces que el gobierno o el Estado, el campo político y del poder en general, es un referente que marca la relación de los intelectuales mexicanos con su público y que determina la configuración del campo de la cultura; aun, cuando se percibe la reducción de su injerencia directa y patrocinio en las últimas décadas del siglo Xx.

Especialmente en la década de los ochenta, con la crisis económica y fiscal, el papel activo del Estado en el campo de la cultura va a cambiar, cuando retira apreciablemente su patrocinio. Durante De la Madrid (1982-1988), los intelectuales gozaron de una mayor independencia y autonomía, pero en buena medida como resultado de la desinversión estatal en la cultura. ${ }^{24}$ Se encontraron en una situación ambigua, que bien expresa Ricardo Pérez Montfort en su trabajo sobre la cultura nacional en las últimas décadas del siglo xx: "una especie de esquizofrenia imperaba en los ámbitos creativos e intelectuales del país: por un lado se insistía en la necesidad de una cultura independiente y vigorizada por los nuevos tiempos, pero por otro, se añoraban los días en que desde el gobierno se abrían los cauces presupuestales para el fomento y protección de la cultura nacional...". 25

Tan solo en 1982, alrededor de 150 publicaciones periódicas salieron de circulación, así como un gran número de suplementos culturales desaparecieron o se vieron obligados a disminuir su oferta y páginas, todo aparejado con una drástica

\footnotetext{
${ }^{24}$ Desde su campaña presidencial la postura de Miguel de la Madrid fue desvincular al Estado de intervenir directamente en la política cultural. Así se pronunció el 13 de noviembre en Tijuana en contra del monopolio estatal sobre la cultura, apoyado en esta posición por su coordinador de campaña, y luego secretario de Programación y Presupuesto, Carlos Salinas de Gortari. En esta reunión de campaña asistieron intelectuales, académicos y destacados representantes del mundo de las artes, entre ellos: Luis González y González, Gastón García Cantú, Guillermo Bonfil, Henrique González Casanova, Javier Barros, Gloria Salas, Arturo Azuela, Guillermina Bravo, Héctor Azar. Véase: Ricardo Pérez Monfort, "Notas para la revisión de una imposible cultura nacional mexicana a fines del siglo XX y principios del siglo XXI", Fin de siglos, ¿fin de ciclos? 1810, 1910, 2010, coords. Leticia Reina y Ricardo Pérez Montfort (México: Siglo XXI Editores, 2013) 326-327.

${ }^{25}$ Pérez 325.
} 
disminución de los anunciantes oficiales, en primer lugar, y comerciales. ${ }^{26}$ De este modo, las publicaciones periódicas que permanecieron en la década requirieron, $\mathrm{o}$ bien estar cobijadas bajo una institución académica-universitaria que subsidiara, aun en un escenario adverso económicamente, su elaboración y distribución, o para las "independientes" asumir la elevación de los costos de producción y asegurarse anunciantes en el Estado o en el sector privado, con lo que se adecuaban a la lógica empresarial y reducían su mercado a un público con capacidad de consumo. ${ }^{27} \mathrm{La}$ crisis golpeaba a toda la producción editorial tanto a la producción de libros como a empresas editoriales y librerías. De 1981 a 1985 se redujo el número de establecimientos dedicados a la industria editorial de 685 a 150 editoras, con un gran porcentaje dependientes de editoriales españolas. ${ }^{28}$

Este escenario de crisis en la cultura generará las condiciones para la neoliberalización del campo a tono con las políticas que en el plano económico ya se venían adelantando desde el inicio del gobierno de De la Madrid. Es un proceso de "reprivatización de la cultura", tal como lo manifiesta Claudio Lomnitz, el modelo de impulso activo del Estado a la expansión educativa y cultural había llegado a su fin con la crisis de 1982. Se reiniciaba una nueva era en la vida cultural mexicana, caracterizada por la privatización de los espacios y una creciente diferenciación entre una proletarizada masa de maestros, con cada vez menos prestigio y estima social, y un estrato de intelectuales privilegiados vinculados a publicaciones académicas junto a una elite cultural que ha logrado vincular el escribir con los negocios. ${ }^{29}$ Según Lomnitz, después de 1982 el gobierno redujo su apoyo a las universidades, en buena medida el gasto en este rubro de redireccionó a subsidios y apoyo a un grupo selecto de "“estrellas' intelectuales" que se ubicaron en escenarios independientes a la universidad y a la academia con publicaciones propias controladas por ellos y en conexión con los medios masivos, en especial la televisión. ${ }^{30}$

En este contexto se desarrollan dos revistas como Vuelta, centrada en lo literario, en el arte y la cultura, pero que participa en el debate político cuando lo considera pertinente, al decir de Octavio Paz, y Nexos, con crítica literaria, notas culturales, pero un mayor énfasis en el análisis de coyuntura y hechos políticos de interés. Vuelta es creada en diciembre de 1976, por Octavio Paz, y se asume como continuidad de la revista Plural que se publicaba en el Excélsior. Sus miembros salen de Plural y fundan otra revista independiente, más controlada por Octavio Paz, quien será su director. Lo acompañan en este proyecto Alejandro Rossi, director adjunto

\footnotetext{
${ }^{26}$ Greaves 366.

${ }^{27}$ Hacia 1982 dejaron de circular cerca de 150 publicaciones periódicas y un buen número de suplementos culturales que se publicaban anexos a otras publicaciones periódicas desaparecieron o se vieron obligados, los que permanecieron, a disminuir de manera apreciable su número de páginas. Greaves 366-367.

${ }^{28}$ Greaves 366-367.

${ }^{29}$ Claudio Lomnitz, “An Intellectual's Stock in the Factory of Mexico's Ruin: Enrique Krauze's Mexico: Biography of Power", Deep Mexico, Silent Mexico. An Antropology of Nationalism (Minneapolis: University of Minnesota Press, 2001) 215.

${ }^{30}$ Claudio Lomnitz, "Narrating the Neoliberal Moment: History, Journalism, Historicity", Public Culture 20.1 (2008): 45.
} 
y miembro del consejo de redacción junto con Gabriel Zaid, Salvador Elizondo, Juan García Ponce, José de la Colina, Kasuya Sakai y Tomás Segovia, ${ }^{31}$ además, se integraría al grupo un joven de la generación del 68, Enrique Krauze, quien con su obra Caudillos culturales en la Revolución Mexicana (1976) gozaba ya de prestigio intelectual tanto entre historiadores como en el mundo de la crítica, además de ser conocido por haber publicado escritos en suplementos político-culturales como $\mathrm{La}$ cultura en México de la revista Siempre!, y en la antigua Plural donde inicialmente ingresó al círculo de Paz. ${ }^{32}$

Por su parte, la revista Nexos surge dos años después, en 1978, impulsada por un consagrado historiador, Enrique Florescano, quien oficia como su director, acompañado de otro historiador en proceso de consagración, Héctor Aguilar Camín. Este último con una investigación publicada, La frontera nómada. Sonora y la Revolución Mexicana (1977), con la que tuvo una excelente acogida y aceptación al plantear otra perspectiva y una nueva manera de escribir la historia y de entender la Revolución Mexicana. Al igual que Krauze, Aguilar Camín participó escribiendo en La cultura en México, pero a diferencia de éste permaneció vinculado a la publicación y al grupo de intelectuales que la rodeaba, tiempo después, aun colaborando en publicaciones como Unomásuno y como integrante y luego director de Nexos. Además de la crónica y el ensayo, se dedicó a la escritura narrativa de cuento y novela.

Junto con Aguilar Camín conformaban el equipo de redacción de Nexos Adolfo Castañón y Julio Frenk. La revista se constituyó bajo tres secciones que tenían sus respectivos consejos editoriales: "Sociedad e historia", lo integraban Guillermo Bonfil Batalla, Pablo González Casanova, Lorenzo Meyer, Alejandra Moreno Toscano, Carlos Pereyra, José Luis Reyna, Luis Villoro, Arturo Warman; "Ciencias", constituido por Luis Cañedo, Eugenio Filloy, Cinna Lomnitz, Daniel López Acuña, José Warman; y "Literatura y arte", integrado por Carlos Monsiváis, Yolanda Moreno Rivas, Antonio Alatorre, José Joaquín Blanco. ${ }^{33}$ Varios de los integrantes del grupo Nexos habían pertenecido al grupo de La cultura en México, en cierta medida la revista de los historiadores Enrique Florescano y Héctor Aguilar Camín había integrado la tradición y el trabajo de los colaboradores de la revista de Carlos Monsiváis.

A su vez, la revista Vuelta tenía un mayor despliegue en elaboraciones referidas al mundo de la literatura en México y Occidente, precisamente por el origen y el carácter de sus integrantes. Desde un principio se ligó a una defensa de la pureza del oficio de escritor basado en la independencia del poder como carácter definitorio del intelectual y garantía para el ejercicio de su función y servicio a la sociedad. En su posición política se asumió como una revista defensora del pensamiento liberal y en contra de los considerados totalitarismos; crítica del marxismo y del socialismo realmente existente en Europa del este y en la Unión Soviética, se tornaba en ocasiones rabiosamente anticomunista.

\footnotetext{
${ }^{31}$ Gerardo Ochoa Sandy, “'Vuelta' y 'Nexos': Vidas paralelas, vecinos distantes”, Proceso 796 (1992): 52.

${ }^{32}$ Krauze, "El historiador liberal" 42-44.

${ }^{33}$ Ochoa, “"Vuelta' y 'Nexos" 53.
} 
En este sentido, la revista Nexos, en el campo político, surgió en parte como respuesta a la postura de la revista de Paz. Se erigía como una publicación progresista y de izquierda, a la vez crítica de los procesos autoritarios y con una postura distanciada de la izquierda tradicional y dogmática, y si bien mantenía un nexo con el campo de la literatura, su interés era aún más interdisciplinario y con un vínculo mayor con las críticas y discusiones surgidas desde el ámbito universitario y el desarrollo de las ciencias sociales y la Historia en México. ${ }^{34}$

El tema y la postura con respecto a la izquierda marcaría una de las diferencias fundamentales entre las dos revistas, Vuelta era leída como una revista literaria con una postura política liberal de derecha, pro-empresarial, mientras Nexos era percibida como de izquierda socialdemócrata, de opinión y cultura; esta diferenciación política se demarcó claramente bajo la polémica suscitada entre diciembre de 1977 y enero de 1978 por el enfrentamiento de Octavio Paz y Carlos Monsiváis alrededor del socialismo en la URSS y la izquierda mexicana. ${ }^{35}$ Cada una de las revistas asumió un lado en el debate. José Agustín en el segundo volumen de La tragedia mexicana llega a afirmar que de dicho debate se nuclean dos "minimafias" intelectuales que van a conseguir los favores del gobierno de turno, en materia de financiamiento y política cultural, en la década de los ochenta y noventa, esas dos "minimafias", según la apreciación de su autor, serían identificables alrededor de los colaboradores e integrantes de revistas como Vuelta y Nexos. ${ }^{36}$

La revista Vuelta en su primer número de diciembre de 1976 afirmaba en un artículo de presentación, escrito por Octavio Paz, que la literatura era el oficio y la pasión que los convocaba a ese espacio, y la función de la literatura no era salvar al mundo, sino simplemente presentarlo o trascenderlo, ya esta evidencia de la realidad incluye su crítica. ${ }^{37}$ Por el contrario, la presentación de la revista Nexos en su primer número de enero de 1978 criticaba que la organización de la cultura mexicana estuviera reducida "a las preferencias de la vida literaria", cuando las necesidades de comprensión de la realidad mexicana imponían mayores perspectivas y espacios de análisis; de este modo, proponían una mayor integración y comunicación del conocimiento especializado que se produce en las universidades para contribuir a la ampliación de la investigación académica.

En este sentido, Nexos se planteaba como "lugar de cruces y vinculaciones, punto de enlace para experiencias y disciplinas que la especialización tiende a separar... ". ${ }^{38}$ Ambas revistas, sin embargo, en los ochenta comenzaron a ser identificadas con el

\footnotetext{
${ }^{34}$ Van Delden, Maarten (2002), "Conjunciones y disyunciones. La rivalidad entre Vueltas y Nexos", El laberinto de la solidaridad. Cultura y politica en México 1910-2000, eds. Kristine Vanden Berghe y Maarten Van Denden (Amsterdam: Rodopi, 2002) 106-108.

${ }^{35}$ Esta querella es sintetizada por Hector Aguilar Camín en su artículo en Nexos. Héctor Aguilar Camín, "Mi querella con Paz", Nexos 448 (2015): 64-65.

${ }^{36}$ José Agustín, La tragicomedia mexicana 2. La vida en México de 1970 a 1982 (México: Editorial Planeta Mexicana S.A., 1992) 213-215.

${ }^{37}$ Octavio Paz, "Vuelta", Vuelta 1 (1976): 5.

38 “Editorial", Nexos 1 (1978): 3.
} 
poder político y económico, en dicha década lograron sobrevivir desde una estrategia comercial y empresarial a la crisis mediante alianzas con empresas y con proyectos al seno del Estado. Y en los noventa llegarán a hegemonizar el campo cultural en su relación con el Estado como constructores de una nueva hegemonía fundada en un ideario neoliberal. Este periodo de hegemonía cultural es sintetizado por Claudio Lomnitz de la siguiente manera:

At the same time that the Mexican state strangled its universities, it did not abandon its patronaje and contact with intellectuals. The De la Madrid (198288) and Salinas (1988-94) gobernments coupled their tight policies toward the university with generous contracts and subsidies to specific intellectual group. The principal groups gravitated around two literary/political journals: Vuelta and Nexos. These two groups accumulated vast cultural power in the $1980 \mathrm{~s}$ and 1990s. Héctor Aguilar Camin, former director of Nexos, member of the '60 generation and erstwhile leftist, was a close friend to Carlos Salinas de Cortari. He created a publishing house Cal y Arena, whose books were widely distributed, publicized by Nexos - controlled public TV Channel 22.

Oh his side, Enrique Krauze, the principal entrepreneur of the Vuelta group [...] and Vuelta began doing business with Televisa, Mexico's televisión giant that had effectively been a communications monopoly for decades, thanks to its special ties to government. Televisa had a largely negative role in Mexico's transition to democracy, a fact that has been widely recognized by independent political observers of Mexico, including the United Nations. This dis not stop self-styled democratic hero Enrique Krauze from becoming one of the company's partners. Krauze is co-owner of Clío, a publishing house devoted to popularizing his versión of Mexican history [....$^{39}$

\section{De Vuelta a Nexos. Una misma hegemonía, aunque compartida}

Comenzando la década de los ochenta el discurso político de Vuelta se radicaliza hacia una postura anticomunista y antiizquierdista, y un discurso radical en contra del Estado y la herencia corporativista de la Revolución Mexicana. En 1981, Paz afirmaba tajantemente la posición de la revista en contra del Estado y de las doctrinas de izquierda marxistas y leninistas. Al primero lo denunciaba como injerencista en la cultura y cooptador y limitante de la necesaria independencia de la labor creativa e intelectual. "No solo es el Estado heredero de la Revolución Mexicana, sino que, a través de sus órganos y agencias, dirige o patrocina... actividades culturales... Gran canal de la movilidad social el Poder institucional seduce, premia, manipula y, a veces, castiga". ${ }^{40}$ De este modo, consideraban, en conjunto como revista, tal como bien caracteriza su postura Avital Bloch en su estudio sobre el neoconservadurismo

\footnotetext{
${ }^{39}$ Lomnitz, “An Intellectual's Stock..." 219-220. Hay que decir aquí que este capítulo del libro de Claudio Lomnitz, Deep Mexico, Silent Mexico. An Antropology of Nationalism, antes fue publicado como un artículo reseña crítica en enero de 1998 en la revista American Journal of Sociology, titulado de la misma manera “An Intellectual's Stock in the Factory of Mexico's Ruin: Enrique Krauze's Mexico: Biography of Power", a tono de crítica al libro de Enrique Krauze Biografia del Poder.

${ }^{40}$ Octavio Paz, “Quinta Vuelta”, Vuelta 60 (1981): 4.
} 
en México, que el "Estado debería limitarse a garantizar las libertades y la equidad política" la vida económica de la sociedad debía ser definida por los grupos privados y por las tradiciones ya arraigadas. Enrique Krauze definía esta postura como "democracia sin adjetivos", ${ }^{41}$ es decir "un modelo de democracia según la cual no se bebe sacrificar excesivamente las libertades en pro de la justicia social". ${ }^{2}$

Dicha postura resultaba funcional a los cambios que sufría el mundo cultural en los ochenta y a las reformas en la senda neoliberal durante los gobiernos de De la Madrid y Carlos Salinas de Gortari, y facilitaría la adaptación a las nuevas circunstancias signadas por el repliegue del Estado de la actividad cultural y el mayor protagonismo de la empresa privada.

En los ochenta, Octavio Paz y miembros de Vuelta se vinculan a órganos privados en la gran prensa y la televisión, El Universal y Televisa se convierten en los aliados que servirán de puente para hacer del grupo director de Vuelta la punta de lanza de la propuesta de la intelectualidad subvencionada por los empresarios como apoyo para gritar su independencia del Estado; ${ }^{43}$ no obstante, el público conocimiento de los vínculos de Televisa con los gobiernos en los ochenta y noventa, y de los apoyos y subvenciones del Estado a la televisora. ${ }^{44}$ Es una elite cultural que manifiesta

\footnotetext{
${ }^{41}$ En el número de la revista Vuelta de enero de 1984, Enrique Krauze publicó un artículo con el nombre "Por una democracia sin adjetivos", que dos años después daría título a un libro que reunía varios ensayos sobre el tema de la democracia y la política en México. En dicho artículo Krauze señalaba que la democracia debía estar por encima de cualquier otro valor o iniciativa política o social, y que la raíz de los problemas en México estaba en postergar la democracia a otras reformas supuestamente más prioritarias. Refiriéndose a la oportunidad que en este sentido tenía el gobierno de De la Madrid, señalaba: "El gobierno tiene un as en la manga olvidado desde la presidencia de Madero: la democracia. Ha sido un ideal revolucionario relegado para otros fines...: el bienestar económico, la justicia social, la afirmación nacional, la paz y la estabilidad. Siempre existen argumentos para limitar, posponer o desvirtuar a la democracia..." Enrique Krauze, "Por una democracia sin adjetivos", Vuelta 86 (1984): 4.
}

${ }^{42}$ Avital H. Bloch, "Vuelta y cómo surgió el neoconservadurismo en México", Culturales 4.8 (2008): 86-87.

${ }^{43}$ Héctor Aguilar Camín en un artículo publicado en Nexos, hace pocos años señalaba las reacciones en contra que había tenido este acercamiento a Televisa por parte de la izquierda, que veía en esto una contradicción para alguien que había salido por la treta que el gobierno de Echeverría, apoyado en la televisora Televisa entonces, habían urdido para acabar con la dirección que ejercía el grupo de Scherer sobre dicho periódico. Para este autor "tuvo que ver en su acercamiento a la televisora el persistente sentimiento de Paz de vivir aislado y asediado, en un mundo hostil" Aguilar, "Mi querella..." 67. Coincide de este modo con lo que afirma Krauze sobre el acercamiento de Octavio Paz a Televisa: "sintiéndose acosado y aislado, Paz respondió a las críticas ampliando su presencia en medios. Ya no solo publicaría en Vuelta, sino en las páginas de El Universal... Al poco tiempo, Paz comenzó a aparecer también, con comentarios internacionales, en el principal noticiero nocturno de la televisión mexicana: 24 Horas, conducido por Jacobo Zabludowsky" Enrique Krauze, "Hombre en su siglo. Octavio Paz: el poeta y la revolución”, Redentores. Ideas y poder en América Latina (México: Random House Mondadori, 2011) 273.

${ }^{44}$ Lomnitz señalaba cómo desde los ochenta el grupo de Vuelta, encabezado por Octavio Paz y Enrique Krauze, se asoció en negocios en el mundo de la cultura con Televisa que había torpedeado el proceso de tránsito y apertura a la democracia, cuando estos intelectuales se promocionaban como paladines de la democracia liberal. Krauze se convertiría en los noventa en socio de Televisa y copropietario y creador de Clio $T V$, empresa de Televisa dedicada a la popularización de su versión de la historia de México a través de la producción y realización de telenovelas históricas y hasta documentales, reconocida por sus esfuerzos a principios de la década de los noventa por revitalizar la figura de Porfirio Díaz a través de la televisión. Lomnitz, “An Intellectual's Stock...” 220-221. 
su adscripción a un nuevo México que se plantea, bajo el triunfo liberal y del libre mercado, opuesto al legado popular y de reivindicación social de la Revolución Mexicana, y cuyo estandarte es la democracia liberal sobre cualquier otro bien. Su poder se incrementa en el campo cultural paralelo al retroceso de la educación pública y la investigación, junto al repliegue de la inversión en la cultura y la privatización del campo que lleva consigo, como en los otros órdenes de la vida social, se daría una mayor concentración del manejo sobre la política cultural y sus escenarios de producción y reproducción en una elite cada vez más reducida.

El énfasis en lo privado y empresarial como punto de apoyo para la labor creativa y garantía de independencia, así como de un mayor poder de juego frente al Estado, era un principio directriz en Vuelta que se manifestaba en la financiación de sus anunciantes, la mayoría provenientes de la iniciativa privada. Según cálculos, en 1992 el 70\% de sus anuncios provenían de la iniciativa privada y el 30\% restante de instituciones del Estado. ${ }^{45}$

Por su parte, Nexos surgió desde los espacios culturales establecidos como escenarios institucionales de origen estatal, la universidad fundamentalmente era su principal nicho, además de instituciones culturales y académicas especializadas, su relación y referente con el Estado era su punto de apoyo para llegar al público; igualmente, esta característica fundamental de la revista se manifestaría en el peso de sus anunciantes: en 1992 el 83\% eran gacetillas del gobierno e instituciones del Estado, y tan solo $17 \%$ de la empresa privada. ${ }^{46}$ La revista Nexos en el año de 1983 pasó a ser dirigida por Héctor Aguilar Camín, quien reemplazaba a Enrique Florescano.

Desde entonces, se le imprimió a la revista un carácter más empresarial, vinculándola, gracias a sus nexos con las universidades y el Estado, a una actividad importante en la agencia de consultorías y asesorías que, junto con los anuncios y la actividad editorial, que luego significaría a finales de los ochenta su articulación con la editorial Cal y Arena, mantuvieron a la revista financieramente. De esta manera, se garantizó su continuidad mientras a través de sus miembros y colaboradores se involucraba a las redes e instituciones definidoras de la política cultural durante los ochenta y los noventa. ${ }^{47}$

Los intelectuales adscritos al proyecto de Nexos apoyaron los procesos de cambio en México que desde el gobierno se impulsaban a nivel económico y político en la década del ochenta, y sobre todo durante el gobierno de Carlos Salinas. Consideraban que se generaba un escenario valioso para sacar al país de la crisis económica y social en que se encontraba sumido. Las propuestas del gobierno Salinas de orientar su política bajo un "liberalismo social" y llevar adelante un proceso de modernización eran leídas como las medidas necesarias para acabar con un Estado antidemocrático, y dar paso a las condiciones que posibilitaran una sociedad más democrática y abierta políticamente.

\footnotetext{
${ }^{45}$ Gerardo Ochoa Sandy, "Las relaciones de los intelectuales con el poder: 'Coloquio"”, Proceso 799 (1992): 52.

${ }^{46}$ Ochoa, "Las relaciones de los intelectuales..." 52.

${ }^{47}$ Aguilar, "Retrato después..." 25-27, 32-33.
} 
De este modo, asociaban la política impulsada por el proyecto neoliberal, de desmonte y repliegue del Estado de anteriores esferas que ocupaba del mundo social y económico, con la mayor democracia y apertura de posibilidades de participación política en el empeño por romper con un sistema político corporativista, autoritario y clientelista. Era una perspectiva gradualista que apoyaba la modernización y las políticas de Salinas como un momento en el tránsito hacia la democracia. En esta dirección, el director de la revista Nexos interpretaba el momento:

Cuando vino la crisis, después del 82, la crisis de pagos, la crisis de crédito, la crisis de inflación, entonces nos dimos cuenta... de que en verdad el Estado no podía más y que no era parte de la solución sino parte del problema. Creo que el primer gobernante mexicano que vio eso con toda realidad e inició el viraje hacia una posibilidad nueva de hacer las cosas fue Miguel de la Madrid... empezamos a vivir una época en que buena parte de las decisiones económicas se devuelven, desde luego, a los grandes capitales privados, pero también a la iniciativa de la sociedad, a las pequeñas y medianas empresas. Estamos entrando a un esquema en donde la sociedad y las fuerzas productivas reales van a ir marcando la pauta y el gobierno tendrá sobre todo una función reguladora y compensatoria. ${ }^{48}$

La coincidencia ideológica de un buen grupo de intelectuales que se reunían alrededor de la revista Nexos, incluido su director, era patente ya en la segunda mitad de la década de los ochenta. De este modo, su acercamiento a las posturas de la revista Vuelta era mayor, aunque la univocidad en este sentido no era tan clara en Nexos, pues los integrantes y colaboradores reconocen la diversidad de la revista y uno de ellos, ${ }^{49}$ Monsiváis en 1993, defendía el carácter plural de la composición de su comité editorial y de las posturas ideológicas que encontraban allí un espacio de expresión. ${ }^{50}$ En lo que coinciden varios comentadores e investigadores del periodo es que las elecciones de 1988 y el posible fraude que dio por ganador de la presidencia a Carlos Salinas de Gortari fue el evento fundamental que unió a ambas revistas en una identidad con el gobierno y en una relación íntima con el Estado durante el sexenio de Salinas. ${ }^{51}$

\footnotetext{
${ }^{48}$ Aguilar, "Retrato después" 20-21.

${ }^{49}$ En 1992, como respuesta a las acusaciones que se hacían a Nexos de connivencia con el Estado, como un grupo cultural con privilegios del poder, como una especie de "mafia" en la cultura, en un artículo editorial la revista afirmaba: “... La trama de los destinos personales ha convertido a los miembros de Nexos en algo más rico y difícil de reunir que un 'grupo cultural'. Se trata, más bien, de una muy diversa colección de adultos que van y vienen por la revista cargando sus propios compromisos individuales, sus propias convicciones políticas, sus propios intereses profesionales, sus propias pasiones. Y, desde luego, sus propios textos". "Nexos y el Coloquio de Invierno". Nexos 173 (1992): 10.

${ }^{50}$ Monsiváis era muy claro al hacer hincapié sobre la diversidad de posturas en Nexos, pero llegaba a considerar en general a la revista como de centroizquierda o socialdemócrata: "Nexos no es uniforme. Me canso de decirlo un tanto inútilmente por lo visto. Entre otros, en Nexos participamos Lorenzo Meyer, Adolfo Gilly, Jorge Castañeda y yo. No es la misma posición que Woldenberg, y tampoco es la misma que la de Luis Miguel Aguilar, Rafael Pérez Gay, Herman Bellinghause. Cuando hago estos distingos llego a la conclusión previsible e inesperada: no hay dos posiciones iguales..." y más adelante aclara que si bien en la revista Nexos "Hay afinidades amistosas y profundas, y hay el origen común en efecto", considera "restringida" su afinidad política con quienes en la revista "consideran democrático o casi" al gobierno de Salinas “o juzgan óptimo el programa de Solidaridad” Monsiváis, "La disidencia crónica” 74.

${ }^{51}$ Carlos Ilades, por ejemplo, señala que la coyuntura alrededor de la elección de Salinas y la fuerte sospecha de fraude fue fundamental para el acercamiento de los grupos Nexos y Vuelta en la defensa de la elección del presidente, motivados en buena parte por el miedo que generó en estos sectores la posibilidad
} 
Lo cierto es que Nexos y Vuelta serían los escenarios de reunión de dos grupos, representados en cada una de estas revistas, que dominaron el escenario cultural de México en los años ochenta y noventa, y competían por los favores del poder y del Estado. El resto del campo intelectual se mantenía en el nicho de las universidades y sus publicaciones, o entre quienes aún en una postura de izquierda defendían su lugar en el campo, intelectuales que encontraban un nuevo escenario en los partidos de oposición para mantenerse independientes al Estado desde una posición crítica. Algunos lograban desde la disidencia mantener su influencia intelectual; estos intelectuales, al margen de la política selectiva del Estado en materia cultural, con su punto de apoyo en las universidades, con cierto juego de autonomía lograron vincularse a una propuesta política con el surgimiento del Partido de la Revolución Democrática (PRD) que aparecía entonces como alternativa progresista en contra del PRI y del modelo de desarrollo que se imponía desde el Estado. No obstante, su peso y ascendiente sobre la política y difusión de la cultura fue de menor alcance en influencia sobre el escenario cultural mexicano. ${ }^{52}$

\section{La confirmación de la hegemonía por el poder}

Con el relevo en la presidencia, en 1988, se afianzaba mucho más al proyecto cultural y educativo que llevaba el Estado en un nuevo marco de liberalización política y económica. Intelectuales vinculados a las revistas Vuelta y Nexos servirían de apoyo ideológico y legitimador a los argumentos que acompañaban el programa de apertura económica y modernización de Carlos Salinas de Gortari.

Durante su campaña presidencial, los intelectuales le prepararon una reunión en Tabasco, durante el discurso de Salinas, de manera muy simbólica, a su derecha estaba Enrique Krauze y a su izquierda Héctor Aguilar Camín. ${ }^{53}$ Las coincidencias de Nexos, de la postura de muchos de quienes escribían allí, incluida la posición editorial y de su director, con el liberalismo de la revista Vuelta se hicieron más fuertes con la aceptación entusiasta del gobierno de Salinas y su proyecto modernizador y liberal. Desde el momento en el que resultó electo presidente en las elecciones del 6 de julio de 1988, contó con el apoyo de intelectuales vinculados a ambas revistas que defendieron su elección ante las sospechas de fraude. El resultado de estas elecciones fue seriamente cuestionado por acusaciones de fraude realizadas por el candidato del Partido Acción Nacional (PAN), Manuel Clouthier, y de Cuauhtémoc Cárdenas, quien se autoproclamó presidente, a pesar de los resultados oficiales, en representación de la asociación de una disidencia del PRI con algunas coaliciones de izquierda, cuya alianza posteriormente dará origen al PRD.

del ascenso al poder del gobierno de la izquierda que representaba Cuauhtémoc Cárdenas. Este apoyo le sería retribuido a ambos grupos durante el sexenio salinista con un apoyo directo del Estado a sus proyectos culturales y a su proyección intelectual. Carlos Ilades, La inteligencia rebelde. La izquierda en el debate público en México 1968-1989 (México: Océano, 2012) 160-165.

${ }^{52}$ Camp 44-46.

${ }^{53}$ Pérez 332. 
La posición de Octavio Paz en contra de la línea editorial de La Jornada y de un buen sector de la opinión que desconocía las elecciones fue la de llamar a aceptar los resultados y que, si bien eran evidentes irregularidades, de allí a no considerar a Salinas como el ganador de la contienda había una gran diferencia; según Paz, el sistema político mexicano de entonces estaba en una encrucijada, o consolidar un sistema de partidos o pasar a las contiendas tradicionales en la historia de México en tiempos decimonónicos, que desconocían elecciones cuando no les eran convenientes los resultados o aislaban a la oposición si resultaban vencedores. ${ }^{54}$

Por su parte, Héctor Aguilar Camín hacía eco a la opinión de Paz, al afirmar que debía terminarse con el "griterío y el inmediatismo" en este debate y llegar al equilibrio; llamaba a una transición pacífica, concertada e inteligente a la democracia. ${ }^{55}$ Enrique Krauze, en la misma dirección de Paz, escribiría a favor de aceptar el resultado oficial de las elecciones para lograr la estabilidad anhelada en la construcción de la democracia, de este modo afirmaba en dos columnas que publicó los días siguientes a las de Paz, el 13 y 14 de agosto, bajo el título de "Oráculos de Tosqueville" en La Jornada: "Si sabemos consolidar en México lo mucho que se ha ganado, el 6 de julio puede ser todavía la fecha histórica de nuestro bautismo democrático". ${ }^{56}$ Lo mismo haría Gabriel Zaid, llamaba a la oposición a que reconociera la necesidad de aceptar las elecciones por su conveniencia en la convivencia y para "darle una tregua al país", pues en un momento de transformaciones democráticas mantener la postura de desconocer las elecciones podía llevar al caos, y en "una curva peligrosa no es el mejor lugar para ponerse tercos". 57

Ya electo presidente, pero aún sin entrar en funciones, en el mes de septiembre de 1988 Salinas encarga a Héctor Aguilar Camín, como director de la revista Nexos, para que reúna un equipo de académicos y de esta forma generar, según palabras de Gilberto Guevara Niebla, uno de los convocados y a la vez miembro de la revista, "muy rápidamente -en un plazo de ocho semanas- un reporte sintético y global del estado de la educación nacional, sus principales rezagos y, asimismo, anticipar los desafíos que se le presentan al sistema escolar en el futuro inmediato". ${ }^{58}$

Este estudio marcaría la hoja de ruta de la política de modernización educativa en sus inicios. El equipo que convocó la revista Nexos de profesionales y algunos expertos en el tema para su realización estuvo conformado por un núcleo base

\footnotetext{
${ }^{54}$ Octavio Paz, “Entreluz: ¿alba o crepúsculo?”, La Jornada, 12 de agosto de 1988: 1, 8.

${ }^{55}$ Hector Aguilar Camín, “Alba, con nubes”, La Jornada, 16 de agosto de 1988: 1, 10.

${ }^{56}$ Enrique Krauze, "Oráculos de Tocqueville”, La Jornada, 13 de agosto de 1988: 10. El 12 de agosto Octavio Paz en La Jornada manifestaba igual optimismo, llamando a no desperdiciar lo avanzado: "Comenzamos ahora a dar los primeros pasos en un territorio desconocido: el régimen pluralista de partidos. Después de haber liquidado de una manera pacífica una tradición política que duró más de medio siglo, ¿seremos capaces de convivir en una democracia abierta, con todos sus riesgos y limitaciones?" Paz, "Entreluz..." 8.

${ }^{57}$ Gabriel Zaid, "País en curva", Proceso 617 (1988): 63.

${ }^{58}$ Gilberto Guevara Niebla, comp., La catástrofe silenciosa (México: Fondo de Cultura Económica, 2003): 7. Se culminaría dicha investigación en 1989 e influyó en el planteamiento del Plan Nacional de Desarrollo con respecto a la política educativa para el sexenio salinista. No obstante, sería publicado a inicios del año 1992 por el Fondo de Cultura Económica bajo el título La catástrofe silenciosa, oficiando como compilador Gilberto Guevara Niebla.
} 
coordinado por Gilberto Guevara Niebla e integrado, además, por Alejandra Romo, Carlos Muñoz Izquierdo y Roberto Arizmendi. Debían elaborar un diagnóstico que describiera y propusiera elementos para una reforma del sistema educativo en todos sus niveles y modalidades. Por otro lado, se llamaron especialistas para la elaboración de artículos sobre diversos temas que le interesaban al Estado. La globalidad de esta investigación fue evaluada y orientada por un Consejo dedicado a este propósito, integrado por Pablo Latapí, José Warman, Clara Jusidman, Rolando Cordera y Héctor Aguilar Camín. ${ }^{59}$

El estudio evidenciaba una realidad de rezago educativo y problemas estructurales en todos los niveles, principalmente evidentes en las tasas de permanencia y calidad del sistema. Se hacía un énfasis especial en la necesidad de emplazar a la sociedad civil a la elaboración de una reforma integral que tuviera como propósito fundamental el mejoramiento de la calidad, dicho llamado debía realizarse, según prescribía el documento, mediante una consulta nacional coordinada por algún organismo estatal o comisión creada para tal fin, que diera la posibilidad mediante audiencias públicas y privadas a la participación de ciudadanos y actores sociales, generando la legitimidad necesaria para la transformación educativa que se colocaba como imprescindible. ${ }^{60}$

Por su lado, el grupo de Vuelta no se quedó sin su participación en el gobierno que prometía una nueva era de modernización y liberalismo a tono con los tiempos. El 7 de diciembre de 1988, seis días después de la posesión presidencial, "con bombo y platillo" se crea el Consejo Nacional para la Cultura y las Artes (CNCA), posteriormente mejor conocido bajo el acrónimo de Conaculta, que se constituye como entidad autónoma adscrita a la Secretaría de Educación Pública, se encargará del campo de la administración de la cultura, con una burocracia adicional y en la que queda incluido el Instituto Nacional de Bellas Artes (INBA), el Instituto Nacional de Antropología e Historia (INAH), el Conservatorio, la Dirección de Publicaciones, entre otras entidades del mundo cultural. ${ }^{61}$ Se erige como un ente autónomo cuyo cargo de dirección dependía directamente del presidente, ${ }^{62}$ y su labor fundamental era la de coordinar las instituciones culturales y la política en este sentido en el país.

Conaculta surgía, muy en la lógica liberal, como un punto de apoyo e incentivo a los artistas, escritores y grupos dedicados a la cultura, con un mayor énfasis en incentivar las expresiones desde la sociedad; léase revistas, empresas editoriales,

\footnotetext{
${ }^{59}$ Guevara 7-8.

${ }^{60}$ Héctor Aguilar Camín y otros, "El estado de la educación”, La catástrofe silenciosa, comp. Gilberto Guevara Niebla (México: Fondo de Cultura Económica, 2003): 26-27. Años después en un artículo publicado en El Universal se revelaba el pago que hizo el gobierno al trabajo realizado por Nexos, alrededor de 250 millones de pesos de entonces. Dicho artículo se elaboró con el ánimo de denunciar supuestos malos manejos de la presidencia, otorgando favores a amigos y políticos allegados a Salinas. Miguel Badillo, “Favoreció Salinas a Aguilar Camín”, El Universal, México, 9 de febrero de 2001: 8.

${ }^{61}$ Josefina Zoraida Vázquez, "La modernización educativa 1988-1994”, Historia Mexicana 46.4 (1997): 930.

${ }^{62}$ Armando Ponce, "Los embates de Octavio Paz y de 'Vuelta' precipitaron la salida de Víctor Flores Olea”, Proceso 804 (1992): 48.
} 
grupos culturales de carácter privado, escritores, artistas, proyectos culturales, antes que a políticas particulares de instituciones. ${ }^{63}$ Establece, paralelo, un Sistema de Creadores, cual copia del sistema de investigadores en ciencia y tecnología, a quienes se estimula con becas según un criterio que se legitima en el reconocimiento de méritos; todo en la razón neoliberal de subsidio a la demanda, que entiende a la sociedad como una suma de individuos que compiten por los recursos del Estado y la sociedad toda, y tienen acceso a ellos según sus méritos.

En esta lógica, se crea el Fondo Nacional para la Cultura y las Artes el 2 de marzo de 1989, con una aportación inicial de 5000 millones de pesos, como una instancia para el apoyo de proyectos culturales con la participación del Estado, la iniciativa privada, intelectuales, creadores, artistas y escritores; en el Fondo se reúnen recursos para el otorgamiento de becas decididas por artistas, intelectuales y creadores que integran la Comisión de Artes y Letras y la Comisión Consultiva. ${ }^{64}$ Estas comisiones fueron conformadas, además, de manera destacada, por integrantes de Vuelta y Nexos, empezando por sus respectivos directores: Octavio Paz y Héctor Aguilar Camín, asimismo, estaban Alejandro Rossi, José Luis Cuevas, Manuel Álvarez Bravo, Víctor Flores Olea, Hugo Hiriart, Ana Mérida, Rufino Tamayo, Alberto Dallal, Guillermo Tovar, Luis Ortiz Macedo y Silvio Zavala. ${ }^{65}$ Antes de la creación del Fondo, el 15 de diciembre, Enrique Florescano había sido nombrado por el director del Conaculta, Víctor Flores Olea, Coordinador Nacional de Proyectos Históricos, para el cubrimiento de esa área. Las comisiones tenían el poder sobre la asignación de las becas millonarias que el Estado suministraba a artistas en letras, música, danza, dramaturgia, artes plásticas y arquitectura, y que dividía en varias categorías. Las cabezas de Vuelta y Nexos en estas posiciones gozaban de una influencia adicional sobre el mundo cultural, en el apoyo para el inicio de las carreras artísticas de jóvenes creadores o la consagración de otros.

En el discurso, reconocido como muy entusiasta, de Octavio Paz el día de la inauguración del Fondo se manifestaban palabras de apoyo al gobierno de Salinas y al proyecto que representaba, así como su correlato en el mundo de la cultura, donde le otorgaba un valor fundamental al campo cultural:

México vive un período de cambios [...] nuestro país penetra en una nueva época de su historia. Damos los primeros pasos, no sin titubeos, por un territorio desconocido y al que debemos poblar con nuestros actos y, en cierto modo, inventar con nuestras obras. Las novedades más visibles son las de orden político y económico: pluralismo democrático y modernización económica. Los cambios en el dominio de la cultura, menos ostensibles, no son menos decisivos. La acción de estos cambios es profunda y a largo plazo: modificar por dentro a las sociedades y sin ellos las otras reformas políticas y sociales terminan por disiparse. ${ }^{66}$

\footnotetext{
${ }^{63}$ Víctor Flores Olea, "Coloquios y circunloquios", Creación y poder. Nueve retratos de intelectuales, eds. Pilar Jiménez Trejo y Alejandro Toledo (México: Editorial Joaquín Mortíz S.A, 1994) 92-93.

${ }^{64}$ Gerardo Ochoa Sandy, "La directora del Fondo Nacional para la Cultura y las Artes. La renuncia de Paz, una gran pérdida; su opinión para el otorgamiento de becas siempre fue "especialmente respetada",, Proceso 798 (1992): 50.

${ }^{65}$ Ponce, "Los embates" 51.

${ }^{66}$ Octavio Paz, "Fondo Nacional para la Cultura y las Artes", Vuelta 149 (1989): 50.
} 
Pero su propuesta estaba definitivamente atada a una concepción liberal sobre el ejercicio de la actividad creativa, consideraba que el Estado debía limitarse a financiar junto con la empresa privada la actividad creadora e intelectual y garantizar la participación de los intelectuales y creadores, una elite consagrada en el campo, en la asignación de recursos para la cultura. En este sentido, más adelante en su discurso valoraba la iniciativa del Fondo:

La creación del Fondo Nacional para la Cultura y las Artes es un anuncio de los tiempos. Por primera vez en la historia de nuestro país se asocian voluntariamente el Estado y los empresarios para fomentar la creación y la difusión de las obras artísticas y literarias. Por primera vez también -cambio inmenso, radical- los escritores y los artistas tendrán la posibilidad de dirigir y orientar a la cultura viva de México, en el dominio del arte, la literatura y la historia, tanto en la provincia como en la capital. En fin, por primera vez todos los que participamos en esta tarea aceptamos como único principio y guía la libertad de creación. ${ }^{67}$

No obstante, tal como se señalaba más arriba, la relación de Vuelta fue más íntima con el poder económico y mediático a través de grandes empresas como Televisa. Lo que respaldaba un discurso en defensa de la libertad del intelectual y creador por fuera de los imperativos y compromisos con el Estado o gobiernos de turno; discurso para el que, supuestamente, los vinculados a Vuelta y la misma revista eran ejemplo.

\section{Vuelta se reafirma ideológicamente}

La caída del Bloque Socialista significará una coyuntura internacional favorable a las posturas políticas e ideológicas del líder del grupo Vuelta, quien con este hecho reafirmó aún más su "liderazgo intelectual" en México. Junto con el subdirector de la revista Enrique Krauze, y con los demás integrantes, Paz plantea la organización de un evento intelectual, político y cultural que anunciara los nuevos tiempos de triunfo de la sociedad de mercado y la democracia liberal. El grupo Vuelta con el apoyo amplio y directo de Televisa, así como de Benson \& Hedges, IBM, Casa Pedro Domecq y del Estado a través de Pemex, ${ }^{68}$ llevó a cabo un mega evento internacional entre el 27 de agosto y el 2 de septiembre de 1990, a diez meses de la caída del Muro de Berlín y la reintegración de Alemania, al que titularon El siglo XX. La experiencia de la Libertad.

Las conferencias y mesas de trabajo se llevaron a cabo en el staff 2 de Televisa San Ángel, cerrado a los periodistas y al público en general, con transmisión a través de los canales privados de televisión, pues, como afirmó Krauze en su momento, "se trata que el diálogo no vaya a romperse por la gritería del público. Se trata de evitar el asambleísmo". ${ }^{69}$ Los invitados internacionales superaron en número a los nacionales, intelectuales y académicos, así como periodistas y políticos, llegaron a debatir

\footnotetext{
${ }^{67}$ Paz, "Fondo Nacional" 52.

${ }^{68}$ Ochoa, "Vuelta' y 'Nexos"” 53.

${ }^{69}$ Armando Ponce, "El episodio que está detrás del pleito de los intelectuales. Krauze impugnó a Fuentes, y Fuentes y Paz rompieron su larga amistad”, Proceso 798 (1992): 48.
} 
alrededor de la caída del socialismo real y el triunfo del liberalismo. La presencia de intelectuales del centro y este europeo, algunos activos participantes en la caída de los regímenes comunistas, fue significativa entre los extranjeros. Para entonces, un buen sector interpretó el encuentro de Vuelta como la defensa a ultranza del libre mercado y la sanción del entierro del socialismo y de la intelectualidad comprometida con el cambio revolucionario.

Entre los invitados internacionales estuvo Mario Vargas Llosa, Agnes Heller, Daniel Bell, Cornelius Castoriadis, Leszek Kolakowski, Juan Nuño, Irwing Howe, entre muchos otros, y entre los nacionales, además de un buen número del grupo de Vuelta, se invitó a Héctor Aguilar Camín, Carlos Monsiváis, Rolando Cordera, Arnaldo Cordova, Luis Villoro, colaboradores o cercanos a Nexos, entre otros. ${ }^{70}$ Aunque no se invitó a Pablo González Casanova, ni a Carlos Fuentes ni a Gabriel García Márquez, acción que se interpretó como un desplante, y a otros intelectuales por sus ideas de izquierda o porque se les consideraba defensores de "regímenes caducos", tales como el cubano. ${ }^{71}$

La organización de las mesas delineaba claramente los intereses del encuentro, entre ellas se pueden destacar: "Hacia la sociedad abierta. Del socialismo autoritario a la difícil libertad, del comunismo a la sociedad abierta"; "La palabra liberada. Los intelectuales y la nueva sociedad, de la literatura cautiva a la literatura en libertad"; "El ejercicio de la libertad, política y economía. De la economía estatal a la de mercado, balance y perspectivas". En su inauguración, la cabeza de la organización del evento, Octavio Paz abrió las mesas con las siguientes palabras: "Muchas personas me han preguntado por qué lo hemos titulado El siglo XX. La experiencia de la Libertad. Diré muy brevemente: porque me parece que la libertad, más que una idea o un concepto, es la experiencia". ${ }^{72}$

La resonancia del encuentro de Vuelta no solo se limitó al terreno ideológico, sino a los enfrentamientos que suscitó a su interior las manifestaciones de patriarca intelectual expresadas por Octavio Paz. En público y ante las cámaras defendió al gobierno y al Estado mexicano cuando Krauze lo calificó de "dictablanda", y en respuesta a la tesis de Mario Vargas Llosa, quien encontraba en la institucionalización de la Revolución Mexicana en el PRI la "Dictadura Perfecta", matizó esta aseveración "por amor a la precisión intelectual" al asegurar que en México existe "un sistema de partido hegemónico". ${ }^{73}$

\footnotetext{
${ }^{70}$ Patricio Eufracio Solano, "El liderazgo intelectual de Octavio Paz y el encuentro Vuelta", Revista Digital Universitaria 9.9 (2008): 8. http://www.revista.unam.mx/vol.9/num10/art78/int78.htm (28/11/2018).

${ }^{71}$ Cuando se le preguntó a Krauze por qué no se había invitado a Carlos Fuentes y a Gabriel García Márquez, en directa referencia a su postura en contra de la posición política de estos intelectuales frente al régimen en Cuba respondió: "Yo no voy a invitar a un poeta que haga loas al comunismo... no invitamos a intelectuales que defiendan a dictaduras comunistas. Se trata de hablar sobre la experiencia de la libertad, no hacer loas a las dictaduras" Ponce, "El episodio que está detrás del pleito de los intelectuales..." 48.

${ }^{72}$ Eufracio 7.

${ }^{73}$ Ponce, "Los embates" 49.
} 
A su vez, a los intelectuales de izquierda vinculados con la revista Nexos, conferencistas en el encuentro, les tocó enfrentar lo que consideraron agravios. A Monsiváis, por ejemplo, quien estaba en la mesa "La palabra liberada. Los intelectuales y la nueva sociedad", conducida por Enrique Krauze, Paz intervino refutándolo después de su conferencia y no se le dio oportunidad de réplica a pesar de que la pidió, aduciéndose límites de tiempo; por su parte, en el caso de Arnaldo Córdova y Luis Villoro, que participaron como únicos conferencistas mexicanos en la mesa "Hacia la sociedad abierta. Del socialismo autoritario a la difícil libertad", Krauze, quien era también el director del debate, según Córdova, lo invitaba a hablar para luego quitarle la palabra al minuto, sin dejarlo culminar su intervención, y cuando Octavio Paz se refirió a su conferencia "en tono ofensivo", no le dejó contestarle y allí cerró el debate. ${ }^{74}$

El encuentro de Vuelta sirvió para afianzar la imagen del grupo y reafirmar su postura política liberal y anticomunista; era un apoyo a la senda de transformaciones que se daba en el gobierno, pero a la vez, una ratificación, en los hechos, de su postura frente al Estado y de su concepción de los intelectuales y los creadores. Mientras manifiesta su simpatía y apego al proyecto Salinista mediante declaraciones de Paz y el propio Krauze, por otro lado, consideraban que el creador se debe a la sociedad, entendida como el público y los patrocinadores: empresarios, y no al poder político, léase gobierno y en su acepción más amplia: Estado. Si el Estado financia y apoya, se pierde independencia, pues según Paz "los gobiernos dan poco y quitan mucho. La independencia ha sido y es uno de los principios invariables de los que hacemos Vuelta", ${ }^{75}$ a lo que Krauze hace eco cuando afirma por su lado: “... fuera de contar con un pequeño porcentaje de anunciantes del gobierno en nuestra revista, Vuelta no tiene ni quiere tener relación alguna con el poder". ${ }^{76}$

La experiencia de la Libertad le dio una figuración pública y política a Vuelta, ratificándola como representante de un grupo cultural hegemónico vinculado con los grandes medios de comunicación y con la propuesta de privatización cultural a través de una mayor participación empresarial en la cultura. El otorgamiento del premio nobel de literatura a Octavio Paz, anunciado en octubre y entregado en la ceremonia en diciembre de 1990, le daría definitivamente la altura de institución en el campo cultural mexicano, convirtiéndolo en referente obligado del Estado para su intervención en el mundo de la creación, el arte y la cultura. Paz era definitivamente el patriarca incuestionable de la cultura mexicana.

\section{Una hegemonía en disputa. Nexos en su Coloquio de Invierno}

Este equilibrio relativo alcanzado de manera más clara desde la elección de Carlos Salinas, que se manifestaba en una coincidencia política en muchos aspectos

\footnotetext{
${ }^{74}$ Héctor Rivera, "Cuando los dioses descienden del Olimpo... Cómo se han enfrentado Paz y Fuentes a sus adversarios”, Proceso 798 (1992): 53.

${ }^{75}$ Ignacio Ramírez, “Octavio Paz replica a Flores Olea: 'La conciencia de los escritores de Vuelta no está en venta; busque clientes por otro lado", Proceso 800 (1992): 55.

${ }^{76}$ Krauze, "El historiador liberal" 52.
} 
entre los dos grupos que aparecían controlando el campo cultural mexicano pronto se rompería. El avance del grupo vinculado con Aguilar Camín en su relación con el gobierno de Salinas sería el generador del enfrentamiento que escindiría el campo cultural mexicano a principios de la década de los noventa. Era una disputa por el control de las instancias de decisión en la cultura y un enfrentamiento entre posturas sobre la relación de la cultura con el poder.

Nexos continuó oficiando como grupo de especialistas asesores en materia de la reforma educativa para el gobierno de Salinas. En 1991, entre los meses de mayo y junio, Nexos sería el encargado de llevar adelante dos investigaciones, nuevamente bajo la coordinación de Gilberto Guevara Niebla, para Presidencia de la República con el apoyo del Instituto Nacional de Estadística y Geografía (INEGI). Un estudio sobre la educación primaria donde se tomó una muestra de escuelas primarias y se aplicaron entrevistas a profesores y directores, así como encuestas, y otro estudio sobre las escuelas normales como lugar donde se forman los profesores de primaria, el cual también se basó en entrevistas y encuestas que, además de vincular a los directores y profesores, involucraron a los alumnos como futuros docentes. En ambos estudios se recogió información valiosa como base del diagnóstico de la situación de la educación básica y de los docentes, tanto desde su composición y características, como sus demandas educativas. ${ }^{77}$ Además, según muestra Miguel Badillo, entre 1991 y el primer semestre de 1992, Nexos realiza un estudio para Presidencia: "América del Norte. Evaluación del desempeño educativo", donde analiza la educación en varios establecimientos educativos en Estados Unidos con el ánimo de comparar con el sistema mexicano y llegar a conclusiones propositivas para la reforma educativa en curso. ${ }^{78}$

En este contexto, Nexos tendría su oportunidad para generar un escenario de debate que le diera una figuración pública como grupo cultural con un papel también hegemónico en el campo, en disputa con Vuelta y en competencia por la legitimidad y los favores del poder. En una charla informal, en casa de Héctor Aguilar Camín, durante una comida en honor a Fernando Benítez, con Carlos Fuentes y Jorge G. Castañeda, se planificó la posibilidad de realizar un gran evento de reflexión sobre la situación de México en el nuevo contexto y las transformaciones que se estaban dando a principios de la década de los noventa. La propuesta pasaría a la revista Nexos, con el entusiasta apoyo de Rolando Cordera y Pablo González Casanova. ${ }^{79}$

\footnotetext{
77 "La escuela primaria: El aula que quedó". Nexos 170 (1992): 31-38. Este escrito es una compilación y análisis de datos estadísticos sobre la educación seleccionados de investigaciones coordinadas por Gilberto Guevara Niebla y bajo la dirección de Nexos y patrocinada por la Presidencia de la República entre mayo y junio de 1991. Una investigación comprendió el estudio de escuelas primarias y llevó a cabo 2820 entrevistas a profesores de primaria y a 642 directores, se incluyó un cuestionario "auto-aplicado" para profesores de primaria que abarcó a 2780 encuestados; la otra investigación fue sobre escuelas normales, realizada a través de entrevistas a 184 directores, 556 profesores y 742 alumnos. Fueron investigaciones que contaron con un gran apoyo del Estado en la movilización de recursos necesarios para llevarlas adelante, instituciones como el Instituto Nacional de Estadística y Geografía (INEGI) sería la encargada de levantar las encuestas y el análisis estadístico. Cf. "La escuela primaria..." 31.

${ }^{78}$ Badillo 8. El artículo de Badillo consigna pruebas de pagos por ese proyecto entre septiembre de 1991 y julio de 1992 .

${ }^{79}$ Gerardo Ochoa Sandy, “Cuenta Aguilar Camín el origen del Coloquio de Invierno y afirma que estarán
} 
Se propondría como un evento universitario en remembranza de los coloquios de invierno y verano que en la década de los sesenta y setenta organizó Pablo González Casanova junto con Carlos Fuentes, Enrique González Pedrero y Víctor Flores Olea en la Facultad de Ciencias Políticas y Sociales de la Universidad Nacional Autónoma de México (UNAM), donde se llamaba a académicos, invitados internacionales destacados en las ciencias sociales contemporáneas a dar conferencias, y se organizaban seminarios intensivos con la teorías y discusiones más actuales entonces. ${ }^{80}$ Se planteó la realización de un Coloquio de Invierno, en un momento en el que se percibían profundas transformaciones en México, se consideraba que se estaban dando pasos a una sociedad más abierta y democrática con el fin de la hegemonía del PRI, y que propuestas como el "liberalismo social” y la modernización apuntaban a una reestructuración clara de la relación del Estado con la sociedad, en un contexto de crisis de las propuestas alternativas al modelo capitalista y liberal de desarrollo.

Por su parte, Jorge G. Castañeda, uno de los forjadores de la idea del Coloquio, aseveraba que se planteó la necesidad de llevar a cabo un evento "con gente progresista, por no llamarla de izquierda, de diversas partes del mundo, para tratar los grandes cambios de nuestro tiempo. Porque para la sensibilidad progresista, cada vez había la impresión de que se encontraba en un aparente desamparo y derrota; y por otro lado el triunfo de los Estados Unidos y el libre mercado"; de este modo, se expresó la inquietud en diversas reuniones sociales de colegas académicos, intelectuales y amigos, y surgió, según Castañeda, "la voluntad de organizar el Coloquio, vinculado a la Universidad, como institución de reflexión, investigación y estudio". ${ }^{81}$

La propuesta caería muy bien, por sus claras identidades y coincidencias, al presidente de Conaculta Víctor Flores Olea, quien la aprobó y se vinculó institucionalmente apenas se le dio a conocer y se recurrió a él en busca de apoyo. Asimismo, al plantearle la idea al rector de la UNAM, José Sarukhán, éste la encontró coincidente con su interés de "traer figuras intelectuales de primer orden a hacer temporadas a la UNAM". ${ }^{22}$ El Coloquio de Invierno para 1992 estaría organizado por Conaculta, la UNAM y el grupo Nexos, como gestionadores de las fuentes de financiamiento y logística. ${ }^{83}$ Se realizó del 10 al 21 de febrero de 1992, bajo el título

\footnotetext{
representadas todas las corrientes de pensamiento", Proceso 797 (1992): 52.

${ }^{80}$ Víctor Flores Olea recuerda aquella experiencia en una entrevista en 1993: "De 1959 a 1975 fuimos directores de la Facultad de Ciencias Políticas y Sociales, en ese orden, Pablo González Casanova, Enrique González Pedrero y yo. Hacemos un esfuerzo de seriedad académica y de vitalidad universitaria, organizamos grupos piloto de estudio intensivos y, desde luego, durante más de 10 años, cursos de invierno y de verano a los que asisten algunas de las grandes inteligencias de aquellos años: Herbert Marcuse, André Gorz, Lezek Kolakowski, Umberto Cerrono, Rossana Rosanda, Roger Garaudy, Susan Sontag, Lucien Goldman, Ralph Miliband... La gran tarea fue poner a los universitarios al día y en contacto con el nivel contemporáneo del pensamiento universal, al menos en el campo de las ciencias sociales. Este fue el propósito profundo de todo aquello". Flores 85-86.

${ }^{81}$ Ignacio Ramírez, "Lo organizan la UNAM, el Consejo de Cultura y Nexos. Octavio Paz acusa de unilateralidad al Coloquio de Invierno y no asistirá”, Proceso 796 (1992): 51.

82 Ochoa, "Cuenta Aguilar Camín..." 52.

${ }^{83}$ En un artículo editorial de Nexos se señala, buscando desmentir las aseveraciones que atacaban al Coloquio
} 
Los grandes cambios de nuestro tiempo. La situación internacional, América Latina y México, en la Ciudad Universitaria en el auditorio Alfonso Caso, estaba abierto al público en general y a la prensa y fue transmitido por el recién convertido en canal del Estado, Canal 22, que hizo sus emisiones de prueba con las sesiones del Coloquio; a su vez, la radio universitaria fue otro vehículo de difusión y transmisión del evento.

Contó con la asistencia y participación de historiadores, científicos sociales destacados en distintas disciplinas, escritores, periodistas, y se promocionó como un espacio para el debate y análisis de los grandes cambios de nuestro tiempo, cuyos escenarios abarcaban la situación internacional, Latinoamérica y México. Las múltiples sesiones se organizaron como seminarios con mesas de debate y conferencias magistrales. Se calcula la participación como conferencistas de alrededor de 100 intelectuales y académicos mexicanos y extranjeros. Entre los invitados estaba Gabriel García Márquez, Carlos Fuentes, Eric Hobsbawn, Perry Anderson, Regis Debray, Enrique Florescano, Carlos Monsiváis, Pablo González Casanova, Luis González y González. Según Aguilar Camín estaban representadas todas las franjas “desde las posiciones liberales más puras, como las de Hernando de Soto, por ejemplo, hasta las posiciones de izquierda marxista, socialista o socialdemócrata, como podrían ser Adolfo Sánchez Vásquez, Eric Hobsbawn, Regis Debray. Los criterios fueron prestigio y solidez intelectual" ${ }^{84}$ No obstante, la percepción en la prensa era que el Coloquio había sido organizado por gente de izquierda contrapuesta al grupo que representaba Octavio Paz, y se interpretaba como una respuesta al encuentro organizado y convocado por Vuelta hace dos años, ${ }^{85}$ se llegaba a afirmar, incluso, que Carlos Fuentes era el cerebro detrás de esta revancha, ${ }^{86}$ mientras se recordaba que hace dos años no había sido invitado al evento de Octavio Paz. ${ }^{87}$

El Coloquio de Invierno resultó un evento fundamental por la hegemonía cultural en la relación con el poder y el Estado, a partir de él se generó una seria disputa en el terreno de lo simbólico por el dominio público del campo de la cultura entre grupos intelectuales que pugnaban por la hegemonía, por definir su peso y el carácter de su relación con el poder político y económico.

\section{El enfrentamiento Vuelta y Nexos. Escisión del campo}

Desde muy temprano los ataques de Octavio Paz se hicieron sentir, con lo que marcó la pauta del coro de sus seguidores en Vuelta y medios de prensa

\footnotetext{
bajo la premisa que lo hacía aparecer como un abuso en el uso de los recursos de los contribuyentes para un evento que beneficiaba a un grupo de intelectuales, que de los 1170 millones de pesos mexicanos que costó el evento 1000 correspondieron a aportaciones privadas. Cf. "Nexos y el coloquio" 8.

${ }^{84}$ Ochoa, “Cuenta Aguilar Camín” 52.

${ }^{85}$ Ramírez, "Lo organizan la UNAM" 50-51.

${ }^{86}$ Armando Ponce comenzaría uno de sus artículos sobre el tema en Proceso, alimentando esta leyenda de la siguiente forma: "Carlos Fuentes no es solo uno de los animadores del Coloquio de Invierno y su estrella principal, sino el origen y el centro de la polémica que éste despertó, y cuya magnitud ha conmovido y dividido como nunca al medio intelectual mexicano". Ponce, "El episodio que está detrás del pleito de los intelectuales" 48.

${ }^{87}$ Ponce, "El episodio que está detrás del pleito de los intelectuales" 48-49.
} 
acompasados por Enrique Krauze. El 3 de febrero, unos cuantos días antes del inicio del Coloquio, Octavio Paz hizo pública su no aceptación de la invitación que le hiciera José Sarukhán y Víctor Flores Olea a participar en el evento. Sus argumentos eran que se le había invitado tarde, hasta la segunda quincena de enero, y que no estaba de acuerdo con la organización "unilateral" del Coloquio. Cuando el 10 de febrero durante la sesión de preguntas, después del presídium, un periodista indagó sobre las razones de Octavio Paz, de la invitación tardía y la supuesta unilateralidad del Coloquio, Aguilar Camín respondió que al mismo tiempo que Paz fueron invitados Arnaldo Córdova, el embajador Flores de la Peña y otros intelectuales, y ninguno declinó la invitación al Coloquio; con respecto a la unilateralidad, Flores Olea insistió "en el carácter plural del Coloquio" inscrito en el sentido "universal del debate académico de la Universidad". ${ }^{8}$

Los medios explotarían esta desavenencia contra el Coloquio, y llenarían sus páginas de innumerables elucubraciones que muchas veces rayaban en el chisme. No obstante, Paz y su grupo no se quedarían quietos a pesar de que algunos de sus integrantes participaron en el Coloquio, la cabeza del grupo se había manifestado en su contra y Krauze no había sido siquiera invitado. El 7 de febrero, Paz presentó su renuncia al director de Conaculta, Víctor Flores Olea, como miembro de la Comisión de literatura del Fondo Nacional para la Cultura y las Artes. En la comunicación de su dimisión afirmaba que había aceptado participar en el Fondo bajo el "único principio y guía" de la "libertad de creación", pero que ahora renunciaba pues el Conaculta, además de haberse convertido en una institución burocratizada, en su accionar había sido progresivamente viciado "por la parcialidad, el favoritismo y la política de cooptación y neutralización de las voces disidentes". ${ }^{89}$ De este modo, Paz esgrimía uno de los argumentos propios de Vuelta, la defensa de la independencia frente al Estado para garantizar la actividad creativa y de crítica propia de los intelectuales, argumento que tomaba expresión cuando se sentían sobre todo presa de algún agravio o exclusión del poder.

Su postura estuvo concentrada en un principio en señalar la culpa del agravio en la figura de Víctor Flores Olea más que en Nexos o en el rector de la UNAM. Además de la renuncia hecha pública, en una entrevista que concedió a Proceso con Ignacio Ramírez, respondió a la pregunta de cómo explicaba su no participación en el Coloquio de la siguiente manera:

No fui yo el único excluído (sic). En cuanto a mi caso: Flores Olea nos dijo a Krauze y a mí que se trataba de "un olvido lamentable". Excusa ridícula... Fue una exclusión deliberada, como la de Enrique Krauze, Gabriel Zaid, Jorge Hernández Campos y muchos otros. Más tarde, temerosos quizás del escándalo que podría provocar su parcialidad... decidieron invitarnos. Fue un gesto tardío, insincero y acompañado de muchas evasiones y rodeos. Al final no invitaron a Enrique Krauze. Algo muy mezquino. Ni Flores Olea, ni el Rector,

\footnotetext{
${ }^{88}$ Ignacio Ramírez, "En la conferencia de prensa. Flores Olea: Los temas y los invitados prueban la enorme apertura del Coloquio", Proceso 797 (1992): 51-52.

${ }^{89}$ Octavio Paz, “La renuncia de Paz”, Proceso 797 (1992): 51.
} 
dos funcionarios públicos, pueden expulsar a nadie del discurso intelectual. Han cometido una falta grave..$^{90}$

El problema fundamental era ese, el Estado se valía de su poder para favorecer, según Paz y compañía, al grupo que se disputaba con ellos la hegemonía sobre el manejo de la cultura. ${ }^{91}$ Cuando en el encuentro Vuelta, dos años antes, decidieron sus organizadores excluir a intelectuales por sus posturas políticas o ideológicas, además de restringir el acceso al público, en esta lógica, no había qué reprochar, pues era un evento con directrices libres gracias a que el origen de sus recursos era privado; el Estado entonces, manifiesta lo público, y como grupo de intelectuales y escritores debía ser incluido de una manera más protagónica. Pues, bajo este raciocinio, es "natural y legítimo que un grupo de escritores, unidos por estas o aquellas ideas, se reúnan para discutir temas de su elección y que inviten a las personas que gusten”, es decir, esta legitimidad la da que cuenten con recursos dados por privados, como ellos, pero empresarios. "Todo cambia si es una institución oficial la que patrocina la junta. Es ilegítimo y reprobable que las instituciones tomen partido, se alíen con un grupo y excluyan a otros", ${ }^{92}$ pues el Estado es de todos y sus recursos son públicos.

De este modo, lo que les resultaba "profundamente reprobable es que una institución nacional como la universidad, y una dependencia gubernamental, como el Consejo, se conviertan en patrocinadores de un grupo y de que tomen abiertamente partido". A pesar de la defensa de Flores Olea, diciendo que las iniciativas de Vuelta y del mismo Paz también fueron varias veces apoyadas, como la de otros escritores y artistas, y que presupuestaban apoyar la realización de eventos futuros de la misma magnitud donde seguramente Vuelta sería uno de los protagonistas, la respuesta de Paz fue tajante y pública: "la conciencia de los escritores de Vuelta no está a la venta. Busque clientes por otro lado". ${ }^{93}$ El peso en el mundo cultural mexicano de Octavio Paz y del grupo Vuelta se hizo sentir, cuando por orden presidencial, el 27 de marzo, Víctor Flores Olea fue cesado de sus funciones como director del Conaculta y en su lugar se nombró a Rafael Tovar y de Teresa, quien desde hace un año ejercía como director de Instituto de Bellas Artes. Al poco tiempo el nuevo director de Conaculta lograría el regreso de Octavio Paz al Fondo y su mayor vinculación con el desarrollo del Sistema Nacional de Creadores. ${ }^{94}$

\footnotetext{
${ }^{90}$ Ramírez, "En la conferencia de prensa" 51. Cursivas en el original.

${ }^{91}$ En el número de la revista Vuelta de marzo estos argumentos aparecen más desplegados, en el artículo "Coloquio o cuento de invierno", el primero de la serie "La Conjura de los Letrados", que se terminarían de publicar en abril. Allí Paz narra mayores pormenores y considera como explicación de que no se haya invitado a Enrique Krauze, la influencia de Carlos Fuentes sobre Víctor Flores Olea, a quien se dirige de manera fuerte: "Si vetar a un adversario es poco generoso, es inmoral que un funcionario se sirva de la autoridad que el Estado y la sociedad le han confiado para vengar los agravios personales de un amigo. La amistad degenera en complicidad y el sainete burocrático en crónica de los abusos de los mandarines" Octavio Paz, “Coloquio o cuento de invierno", Vuelta 184 (1992): 70-71.

${ }^{92}$ Octavio Paz, "El Coloquio de los incurables”, Vuelta 185 (1992): 10.

${ }^{93}$ Ramírez, "Octavio Paz replica a Flores Olea" 55.

${ }^{94}$ Pérez 335.
} 
Sin embargo, por otro lado, se daba figuración a Nexos, cuando, unos días antes de la salida de Flores Olea, el 23 de marzo, el Presidente Salinas nombró en acto público, luego de la instalación del Consejo de Planeación del Canal 22 en Los Pinos, como director del canal a José María Pérez Gay, colaborador y miembro del equipo de redacción de Nexos. Este evento es tomado con suspicacia por los medios de comunicación, pues se rumoraba que iba a ser nombrado para el cargo Héctor Tajonar, candidato promovido, supuestamente, por Octavio Paz. ${ }^{95}$

Se sumaba a este panorama confrontacional, aún vivos los ecos del Coloquio de Invierno, la demanda interpuesta por Gabriel Zaid al periódico El Nacional considerado del gobierno- por haber publicado un texto de su autoría: "La camiseta inexplicable", sin el debido permiso. Los ataques fueron dirigidos a Fernando Solana Olivares, quien era el subdirector de Publicaciones Culturales de El Nacional. En una "virulenta" defensa de Gabriel Zaid, como su copartidario en Vuelta, se publicaron varios artículos, comenzando por la pluma de Paz, pero apoyado con sendos escritos de Krauze, como subdirector de la revista, y Aurelio Asiain, secretario de redacción. En dichos textos se asociaba a El Nacional con el grupo Nexos por la gestión que había realizado unos meses antes el periodista José Carreño Carlón como su director, reconocido colaborador y columnista de Nexos, hasta que fue nombrado por Salinas jefe de prensa de la presidencia. Atacar a este periódico era continuar en otro frente la lucha contra el grupo Nexos.

En los artículos publicados en abril, de la serie "La conjura de los letrados", Paz expresa claramente su denuncia en contra de la conquista de espacios de influencia política y cultural por Nexos, que el grupo de Vuelta consideraba una amenaza en su posición y hegemonía en el campo de la cultura mexicana. Aunque consideraban al Coloquio como un ataque a la libertad necesaria para la actividad creadora, ya que alimentaba, según ellos, una relación nociva de la cultura con el Estado, fundada en favoritismos y favores mutuos, que excluían a la mayoría de los académicos, escritores e intelectuales, su mayor preocupación inmediata y más sentida estaba en el avance que percibían del grupo Nexos en influencia sobre espacios estratégicos de la política cultural del Estado.

En este marco leían al Coloquio como "una vasta maniobra para apoderarse de los centros vitales e institucionales de la cultura mexicana" ${ }^{96}$ En este sentido, señala Octavio Paz que "la verdadera significación de la polémica" con Nexos es "una cuestión que sobrepasa con mucho a las consideraciones de la política militante de esta o de aquella tendencia", es un asunto de poder sobre el campo de la cultura que, además, enfrenta dos concepciones sobre la relación de los intelectuales con el Estado y la sociedad, una que ve en la articulación del empresariado y la cultura la garantía para que la participación del Estado esté mediada por intereses distintos a los políticos y de partido, y otra que considera al Estado y a las instituciones académicas y culturales las generadoras del escenario intelectual y cultural: con la primera se

\footnotetext{
${ }^{95}$ Ponce, "Los embates" 50.

${ }^{96}$ Octavio Paz, "Palabras mayores y medias palabras", Vuelta 185 (1992): 9.
} 
identifica Vuelta, con la segunda Nexos. Ambas, sin embargo, buscan mantener una posición hegemónica en el mundo de la cultura, y de éste frente al poder.

La preocupación de Paz alrededor del Coloquio destila el temor de verse desplazado por un grupo que, según él, tiene ventaja al aprovecharse de una tradición mexicana que contraviene su idea de libertad intelectual; al concebir "al intelectual no como un crítico del poder sino como su vocero" gana espacios de poder y extiende su influencia mediante alianzas y la conquista del favor oficial. En este sentido dice de Nexos que: “...es una red que envuelve a muchos centros vitales de la cultura mexicana y domina a otros. Mencionaré algunas de sus plazas fuertes: Conaculta, la Universidad, el Instituto Indigenista y el de Antropología, la televisión gubernamental y el diario El Nacional, también del gobierno. Sobre su revista y su editorial llueven los favores oficiales". ${ }^{97}$

El campo cultural a principios de la década de los noventa se encontraba escindido en una disputa por la hegemonía frente al Estado y la sociedad, se podían identificar dos grupos, fuera de ellos había otros que, si bien no estaban en una situación privilegiada frente al poder, en un momento de crisis jugaban un papel en el balance a favor o en contra de alguno de los polos enfrentados.

La vinculación con la asesoría especializada para la reforma educativa planteada por el gobierno de Salinas iba a contribuir a ubicar a los intelectuales nucleados alrededor de Nexos en una posición privilegiada con relación al Estado y por tanto al interior del campo intelectual mexicano. Un año antes de terminar el sexenio de Carlos Salinas, Héctor Aguilar podía decir, aunque con un aire de cierta modestia, "La idea del ideólogo oficial, el intelectual del salinismo, el aprovechador de influencias políticas, me resulta en cierto modo fantástica" y continuaba con una breve exposición del papel de su grupo en la reforma: "Hemos hecho investigaciones educativas para la Presidencia de la República... Creo que hemos colaborado en algo para la reforma educativa, a través de nuestros estudios". ${ }^{98}$

Este enfrentamiento entre los dos grupos continuaría en el terreno de la elaboración de los libros de textos gratuitos de Historia de México para primaria cuya realización había sido encomendada por el gobierno de Salinas al grupo de Nexos, y quienes coordinaron su elaboración fueron Héctor Aguilar Camín y Enrique Florescano. El debate suscitado unió a buena parte del campo intelectual en contra de Nexos y los argumentos generados por Octavio Paz y el grupo de Vuelta en la disputa alrededor del Coloquio de Invierno servirían de munición para el arsenal que se utilizó en el debate. Los libros de texto fueron recogidos de circulación por el rechazo que generaron y el grupo Nexos estigmatizado como un grupo que se había vendido por "las mieles del poder". Vuelta, por su parte, moriría con Octavio Paz en 1998.

\footnotetext{
${ }^{97}$ Octavio Paz, "Los nexos de Nexos", Vuelta 185 (1992): 13.

${ }^{98}$ Aguilar, "Retrato después" 37.
} 


\section{Conclusiones}

Más que conclusiones definitivas se plantean aquí ideas que surgen de la investigación aquí presentada y que requieren mayores desarrollos con un trabajo más amplio y de mayor alcance en la revisión empírica y el análisis sobre el campo intelectual mexicano en las últimas décadas del siglo XX y las décadas que corren del XXI. Es así como se presentan a manera de esbozos problematizadores los siguientes planteamientos:

--Desde un momento de crisis se abre una época en la que el Estado comienza un proceso de repliegue de la vida cultural mexicana, las relaciones de interdependencia entre el campo intelectual y el campo político en México se reconfiguran. Por un lado, la reestructuración del modelo de desarrollo capitalista hacia una economía de mercado financiarizada implicó la reorientación de la relación del Estado con el resto de la sociedad fundadas en la doctrina neoliberal. Es en este contexto es que el Estado disminuye la amplitud e intensidad de su intervención en el campo cultural y lo deja más determinado por las corporaciones privadas y el mercado; algunos intelectuales como Enrique Krauze y Octavio Paz se adaptaron de mejor manera a este nuevo escenario.

No obstante, el Estado seguirá interviniendo en lo cultural y manteniendo su influencia como otorgador de reconocimientos y responsabilidades en el mundo de la cultura a los intelectuales de su elección, aunque cada vez de una manera más focalizada. Pareciera que la política de focalización del gasto en este periodo de transición signada por la doctrina neoliberal se tradujo en el campo de la cultura en México en la escogencia de una manera aún más selectiva de grupos o personalidades reconocidas y consagradas del campo intelectual que sirvieran de intermediarios privilegiados en la focalización de la intervención estatal. Mientras el grupo de Vuelta mantenía un nexo con la literatura y las artes y los sectores que veían la cultura como una empresa, el grupo de Nexos vinculado de manera predominante con las ciencias sociales, pero también con la literatura, era la conexión con el mundo de la universidad y del activismo cultural de un sector de los intelectuales de la izquierda mexicana.

Por otro lado, el Estado vincula a los intelectuales ya no solo con empleos en instituciones culturales o secretarías afines, sino también mediante retribuciones con consultorías, compra de servicios y apoyos localizados a proyectos intelectuales artísticos, creativos y académicos. De este modo, el campo del poder político mantiene su influencia en el campo intelectual, mientras que los escritores, artistas e intelectuales en general que se mantienen cobijados por la universidad e instituciones culturales, si quieren un espacio de incidencia pública y de influencia política amplio requieren necesariamente de la intermediación del Estado o de los medios de comunicación en buena medida monopolizados entonces por intereses afines al proyecto de la clase política dirigente. De allí la necesaria ambigüedad de la postura de Octavio Paz y Vuelta que gritaban la independencia intelectual y denunciaban a otros como la encarnación de la trahison des clercs, ${ }^{99}$ mientras aceptaban puestos y

${ }^{99}$ Este término es acuñado por Julien Benda en la publicación de su ensayo titulado de esa manera, $L a$ 
reconocimientos públicos por parte del Estado; o la aceptación del grupo Nexos de su papel de consultores y socios de la política modernizadora del gobierno salinista.

--El enfrentamiento entre Nexos y Vuelta es la manifestación de la reconfiguración de la sociedad mexicana y de la relación del Estado con ella, de allí que el problema fundamental planteado en el debate sea la relación del campo intelectual con el poder político. Si se siguen las categorías de clasificación de los intelectuales según su actitud ante el campo de poder planteadas por Bourdieu, se puede equiparar a un enfrentamiento entre los "artistas y escritores burgueses", por un lado, que "gozan del reconocimiento del público burgués" y basados en este reconocimiento ofician a veces como voceros de esta clase, y los "sostenedores del arte por el arte", por el otro lado, que mantienen una postura ambigua y contradictoria tanto con respecto a sí mismos como con relación a los que se oponen. Este es el grupo que representa el ideal del campo intelectual. Dividen el mundo bajo criterios estéticos limitados por la actividad creativa por lo que "se ven obligados a rechazar en una sola clase despreciada tanto al 'burgués' obtuso frente al arte, cuanto al 'pueblo' prisionero de las preocupaciones materialistas de la existencia cotidiana"; 100 de esta manera, pueden pasar de posiciones en las que se identifican con el "pueblo", en contra de los "escritores "burgueses", a posiciones aristocráticas cuando buscan atacar a escritores que consideran "socialistas" o vinculados políticamente con causas populares.

Esta lectura de Bourdieu puede ayudar a entender, en términos de la clasificación que propone, el enfrentamiento entre los grupos de Nexos y Vuelta. Tan solo habría que cambiar la palabra "burguesía" por la de "Estado", y redefinir la clasificación para las partes enfrentadas entre aquellos escritores cobijados abiertamente por el favor del Estado, por un lado, que podrían en ciertos escenarios actuar como sus portavoces, y los escritores o artistas que propugnan su independencia del Estado y ante todo su compromiso con el acto creativo en sí mismo. De este modo, así como Bourdieu se refiere a Gustave Flaubert como el arquetipo de la defensa del "el arte por el arte"; ese tipo de intelectual ambiguo que odia y desea al burgués, que lo desprecian y rechazan tanto como se sienten rechazados, puesto "que ellos rechazan solo en cuanto son rechazados por él [el burgués]", lo mismo se podría afirmar de Octavio Paz y su grupo. Evidentemente ni el uno es Flaubert, ni los otros los defensores del arte por el arte de la Francia decimonónica, como tampoco México es Francia. No obstante, Paz y su grupo demonizan al Estado, aunque a la vez desean su reconocimiento; anhelan su aprobación y apoyo, y al mismo tiempo lo rechazan cuando se sienten rechazados por éste. Al igual que en Flaubert, este rechazo y odio se renueva y proyecta sobre los "competidores desleales que obtienen el suceso inmediato y las consagraciones burguesas [léase del Estado para el caso mexicano] solo en cuanto reniegan de sí como escritores". ${ }^{101}$ Es decir, condenan a estos intelectuales que gozan del favor del Estado, pues su figuración pública y consagración no es dada por los méritos de su actividad creativa y el reconocimiento de los integrantes del campo cultural, sino por

trahison des clercs, publicado en 1927 en Francia, y se refería a los intelectuales que habían traicionado su función y compromiso creativo con los imperativos que dictaba la política y el poder. En traducción al español Julien Benda, La traición de los intelectuales (Santiago de Chile: Ediciones Ercilla, 1951).

${ }^{100}$ Bourdieu, Campo de poder 110.

${ }^{101}$ Bourdieu, Campo de poder 111. 
los favores del Príncipe a cambio de su obediencia y servicio. Esto ilustra la centralidad del Estado en el campo cultural e intelectual mexicano en ese entonces y la posición de dependencia del campo con respecto al poder político. Para el Estado los intelectuales seguían siendo un factor fundamental de legitimidad, y para ellos la venia del poder político era la consagración pública deseada.

De este modo, en México no es la burguesía la que va a mantener y generar los espacios que atraigan a los intelectuales para encontrar reconocimiento y su consagración en el campo, es el Estado el que tradicionalmente ha cumplido esta función. Octavio Paz representó a los "sostenedores del arte por el arte" en contra de la contaminación de la militancia política en la actividad creativa y de la intervención política del Estado, pero que a la vez se manejaba en la ambigüedad del deseo por la aprobación del poder político y de los mecanismos de promoción de la cultura por parte del Estado. A su vez, el grupo cuya cabeza más visible era Héctor Aguilar Camín justificaba su papel desde los mismos argumentos que surgían basados en el planteamiento mediador y modernizador desde el Estado. Se planteaban entonces desde una posición de ruptura con un pasado autoritario y corporativista, y abrazaban junto con el poder la liberalización de los mercados y la competencia. Representaban en su discurso un campo cuya autonomía se encontraba aún sujeta al reconocimiento del campo político.

--El enfrentamiento entre Nexos y Vuelta habría que leerlo como parte de un proceso que daría paso a un escenario de atomización y repliegue de los intelectuales de la escena pública. Esta situación se profundizaría en la medida que el Estado retira su reconocimiento explícito a figuras o a grupos destacados del campo como parte del abandono de su protagonismo en el mundo cultural, el cual quedaba reducido al mantenimiento de las instituciones culturales. Salinas sería prácticamente el último presidente que promocionó públicamente a intelectuales y los usó para legitimarse a sí mismo y al Estado. Del gobierno de Ernesto Zedillo (1994-2000) en adelante el campo intelectual mexicano dejó de tener el protagonismo que para el poder político representaba para el sostenimiento de su legitimidad, lo que imperó desde entonces fue una mayor fragmentación del campo y un marcado aislamiento de la escena pública nacional de los intelectuales. Al faltar el apoyo y reconocimiento público del Estado, que al parecer era el que con su política unificaba el campo, lo que pareció imperar fue una intelectualidad refugiada en instituciones como la universidad, en los institutos de investigación y en las instituciones culturales.

\title{
Bibliografía
}

\section{Fuentes primarias}

\author{
Prensa \\ La Jornada (México) 1988, 1992. \\ El Universal (México) 1992, 2001. \\ Nexos (México) 1978, 1992, 2015.
}


Hegemonía cultural disputada en México. Las revistas Nexos y Vuelta enfrentadas...

Vuelta (México) 1976, 1978, 1981, 1984, 1989, 1992.

\section{Fuentes secundarias}

\section{Libros}

Agustín, José. La tragicomedia mexicana 2. La vida en México de 1970 a 1982. México: Editorial Planeta Mexicana S.A., 1992.

Benda, Julien. La traición de los intelectuales. Santiago de Chile: Ediciones Ercilla, 1951.

Bourdieu, Pierre. Campo de poder, campo intelectual. Itinerario de un concepto. Buenos Aires: Editorial Montressor, 2002.

Bourdieu, Pierre. Sociología y cultura. México: Editorial Grijalbo, 1984.

Camp, Roderic A. Los intelectuales y el Estado en el México del siglo XX. México: Fondo de Cultura Económica, 1988.

Guevara Niebla, Gilberto. Comp. La catástrofe silenciosa. México: Fondo de Cultura Económica, 2003 [1992].

Illades, Carlos. La inteligencia rebelde. La izquierda en el debate público en México 1968-1989. México: Océano, 2012.

\section{Capítulos de libros}

Aguilar Camín, Héctor. "Retrato después de la batalla". Creación y poder. Nueve retratos de intelectuales. Eds. Pilar Jiménez Trejo y Alejandro Toledo. México: Editorial Joaquín Mortíz S.A, 1994.

Flores Olea, Víctor. "Coloquios y circunloquios". Creación y poder. Nueve retratos de intelectuales. Eds. Pilar Jiménez Trejo y Alejandro Toledo. México: Editorial Joaquín Mortíz S.A, 1994.

Greaves, Cecilia. "La Secretaría de Educación Pública y la lectura 1960-1985”. Historia de la lectura en México. Coord. ${ }^{a}$ Pilar Gonzalbo. México: El Colegio de México, 1998.

Krauze, Enrique. "El historiador liberal". Creación y poder. Nueve retratos de intelectuales. Eds. Pilar Jiménez Trejo y Alejandro Toledo. México: Editorial Joaquín Mortíz S.A., 1994.

Krauze, Enrique. "Hombre en su siglo. Octavio Paz: el poeta y la revolución”. Redentores. Ideas y poder en América Latina. México: Random House Mondadori, 2011.

Lomnitz, Claudio. “An Intellectual's Stock in the Factory of Mexico's Ruin: Enrique Krauze's Mexico: Biography of Power”. Deep Mexico, Silent Mexico. An Antropology of Nationalism. Minneapolis: University of Minnesota Press, 2001.

Monsiváis, Carlos. "La disidencia crónica". Creación y poder. Nueve retratos de intelectuales. Eds. Pilar Jiménez Trejo y Alejandro Toledo. México: Editorial Joaquín 
Mortiz S.A., 1994. pp. 55-77.

Pérez Montfort, Ricardo. "Notas para la revisión de una imposible cultura nacional mexicana a fines del siglo XX y principios del siglo XXI". Fin de siglos, ifin de ciclos? 1810, 1910, 2010. Coords. Leticia Reina y Ricardo Pérez Montfort. México: Siglo XXI Editores, 2013.

\section{Artículos de revistas}

Aguilar Camín, Héctor. "Mi querella con Paz”. Nexos 448 (2015): 60-77.

Bloch, Avital H. "Vuelta y cómo surgió el neoconservadurismo en México". Culturales 4.8 (2008): 74-100.

Eufracio Solano, Patricio. "El liderazgo intelectual de Octavio Paz y el encuentro Vuelta". Revista Digital Universitaria 9.9 (2008): 1-13.

Krauze, Enrique. "Por una democracia sin adjetivos". Vuelta 86 (1984): 4-13.

Lomnitz, Claudio. "Narrating the Neoliberal Moment: History, Journalism, Historicity". Public Culture 20.1 (2008): 39-56.

Monsiváis, Carlos. "Notas sobre el Estado, la cultura nacional y las culturas populares en México", Cuadernos Políticos 30 (1981): 33-52.

Monsiváis, Carlos. "En el vigésimoquinto aniversario de La cultura en México". La cultura en México. 25 años de La cultura en México 1300 (1987): 36-48.

Nexos. "Editorial”. Nexos 1 (1978): 3.

Nexos. "La escuela primaria: El aula que quedó". Nexos 170 (1992): 31-38.

Nexos. "Nexos y el Coloquio de Invierno". Nexos 173 (1992): 5-17.

Ochoa Sandy, Gerardo. “'Vuelta' y 'Nexos': Vidas paralelas, vecinos distantes”. Proceso 796 (1992): 52-53.

Ochoa Sandy, Gerardo. "Cuenta Aguilar Camín el origen del Coloquio de Invierno y afirma que estarán representadas todas las corrientes de pensamiento". Proceso 797 (1992): 52-53.

Ochoa Sandy, Gerardo. "La directora del Fondo Nacional para la Cultura y las Artes. La renuncia de Paz, una gran pérdida; su opinión para el otorgamiento de becas siempre fue 'especialmente respetada'". Proceso 798 (1992): 50-51.

Ochoa Sandy, Gerardo. "Las relaciones de los intelectuales con el poder: 'Coloquio". Proceso 799 (1992): 52-55.

Paz, Octavio. "Vuelta". Vuelta 1 (1976): 4-5.

Paz, Octavio. "El ogro filantrópico”. Vuelta 21 (1978): 38-44. 
Hegemonía cultural disputada en México. Las revistas Nexos y Vuelta enfrentadas...

Paz, Octavio. “Quinta Vuelta”, Vuelta 60 (1981): 4-5.

Paz, Octavio. "Fondo Nacional para la Cultura y las Artes". Vuelta 149 (1989): 50-52.

Paz, Octavio. “La renuncia de Paz”. Proceso 797 (1992): 51.

Paz, Octavio. "Coloquio o cuento de invierno". Vuelta 184 (1992): 70-7.

Paz, Octavio. "Palabras mayores y medias palabras”. Vuelta 185 (1992): 9-10.

Paz, Octavio. "El Coloquio de los incurables". Vuelta 185 (1992): 10-12.

Paz, Octavio. "Los nexos de Nexos". Vuelta 185 (1992): 12-14.

Ponce, Armando. "El episodio que está detrás del pleito de los intelectuales. Krauze impugnó a Fuentes, y Fuentes y Paz rompieron su larga amistad”. Proceso 798 (1992): 48-51.

Ponce, Armando. "Los embates de Octavio Paz y de 'Vuelta' precipitaron la salida de Víctor Flores Olea". Proceso 804 (1992): 48-51.

Ramírez, Ignacio. "Lo organizan la UNAM, el Consejo de Cultura y Nexos. Octavio Paz acusa de unilateralidad al Coloquio de Invierno y no asistirá". Proceso 796 (1992): 50-51.

Ramírez, Ignacio. "En la conferencia de prensa. Flores Olea: Los temas y los invitados prueban la enorme apertura del Coloquio". Proceso 797 (1992): 51-52.

Ramírez, Ignacio. “Octavio Paz replica a Flores Olea: 'La conciencia de los escritores de Vuelta no está en venta; busque clientes por otro lado"”. Proceso 800 (1992): 55.

Rivera, Héctor. "Cuando los dioses descienden del Olimpo... Cómo se han enfrentado Paz y Fuentes a sus adversarios". Proceso 798 (1992): 52-53.

Scherer, Julio. "Octavio Paz: 'La conciencia es lo contrario de la razón de Estado"”. Proceso 57 (1977): 6-10.

Scherer, Julio. “Octavio Paz: 'Veo una ausencia de proyectos, las ideas se han evaporado"”. Proceso 58 (1977): 6-10.

Van Delden, Maarten. "Conjunciones y disyunciones. La rivalidad entre Vueltas y Nexos". Vanden Berghe, Kristine y Van Denden, Maarten, El laberinto de la solidaridad. Cultura y política en México 1910-2000. Foro Hispánico 22 (2002): 105-120.

Vázquez, Josefina Zoraida. "La modernización educativa 1988-1994”. Historia Mexicana 46.4 (1997): 927-952.

Zaid, Gabriel. "País en curva”. Proceso 617 (1988): 62-64.

\section{Publicaciones en Internet}

http://www.revista.unam.mx (2018) 